\title{
Maiores Navios no Mundo, mais um Desafio no Brasil: uma análise do Programa Nacional de Dragagem
}

\section{Luciano Menegazzo}

Mestre em Economia - Universidade Federal de Santa Catarina (UFSC)

Endereço: Campus Universitário Reitor João David Ferreira Lima Departamento de Economia e Relações Internacionais, Bloco D do CSE - Trindade - Florianópolis/SC

CEP: 88040-900 - E-mail: lucianormenegazzo@yahoo.com.br

\section{Francis Petterini}

Professor - Universidade Federal de Santa Catarina (UFSC)

Endereço: Campus Universitário Reitor João David Ferreira Lima Departamento de Economia e Relações Internacionais, Bloco D do CSE - Trindade - Florianópolis /SC

CEP: 88040-900 - E-mail: f.petterini@ufsc.br

Recebido: 01/11/2016. Aceite: 16/08/2017.

\section{Resumo}

Os navios de carga cresceram em dimensões ao mesmo tempo em que falta manutenção adequada nos acessos aquaviários brasileiros. Consequentemente, é comum ter que esperar a maré subir para manobrar os navios com segurança, o que causa custos de demurrage. O artigo analisa o impacto do Programa Nacional de Dragagem, que visa a mitigar o problema. Usando a metodologia dos controles sintéticos na movimentação de carga por navio em 11 portos tratados, tendo 24 instalações comparativas, encontraram-se indicativos que o programa gerou impacto em quatro deles. A conclusão é que programa é estratégico para comércio exterior, mas precisa ser aprimorado.

\section{Palavras-Chave}

Portos. Dragagem. Controle sintético.

\begin{abstract}
The cargo ships have grown in size, while there was a lacking of maintaining of the Brazilian waterways. Therefore, it is common wait the rising tide to safely conduct the ships, which implies in demurrage costs. The article analyzes the impact of the National Dredging Program, which aims to mitigate the problem. Using the methodology of synthetic controls to model the ship handling in 11 ports treated, with 24 comparative units, we met indicatives that the program caused impact on 4 of them. The conclusion is that the program is strategic for foreign trade, but needs to be improved.
\end{abstract}

\section{Keywords}

Ports. Dredging. Synthetic control.

\section{JEL Classification}

D04. H43. R42. 


\section{Introdução}

O frete e a logística de distribuição de mercadorias são elementos cruciais do comércio, especialmente do internacional, e figuram entre os principais custos de transação (Hornok e Koren 2015; Pascali 2017). Destarte, estima-se que $80 \%$ das mercadorias comercializadas em escala global possuem ao menos um componente que foi transportado por navio, uma vez que este modal permite uma substancial redução desses custos (Rodrigues 2008; Grammenos 2013; Levinson 2013; UNCTAD 2015). Ademais, é fato que nas últimas décadas houve uma tendência de aumento dos navios para se reduzir os custos de frete e logística - e.g.; os dados da Organização Marítima Internacional (IMO) apontam que os conteineiros mais modernos possuem pelo menos 180 mil toneladas DWT (sigla de deadweight tonnage, que representa o peso possível de ser embarcado com segurança) e 16 metros de calado (distância vertical entre a quilha e a linha de flutuação), enquanto os construídos até a década de 1990 possuem no máximo 60 mil toneladas DWT e 12 metros de calado. ${ }^{l}$ Entretanto, para que os países possam usufruir de eventuais ganhos com essa tendência, é necessário adaptar os portos para os novos navios (Notteboom 2004; Imai et al. 2006; Hummels 2007).

Em descompasso com essa tendência, Schwab e Sala-i-Martín (2014) apontam que o Brasil possui uma das piores infraestruturas portuárias do mundo até para atender os navios mais simples - o que é um problema secular que impede a redução dos custos de frete e logística no país (Goularti Filho 2007). Sendo que a literatura nacional de "economia dos portos" indica que tal problema pode ser dividido em três grupos: (i) os de ordem de apoio inadequado de logística e armazenagem, visualmente percebidos pelos grandes congestionamentos de caminhões nas áreas perimetrais aos portos; (ii) os relacionados ao excesso de tempo de desembaraço das cargas, que fica evidente quando se nota que em boa parte dos portos a Receita Federal e a Vigilância Sanitária não trabalham 24 horas por dia, ou

1 Cullinane e Khanna (1999, 2000), Talley (2000), Albertijn et al (2011), Tran e Haasis (2015) e Bernhofen et al (2016) mostram que essa tendência está relacionada com outros quatro fatos: (i) o avança tecnológico da engenharia naval nos estudos de hidrodinâmica e propulsão, que permitiu dar mais estabilidade e velocidade e melhor aproveitamento de combustível nos navios; (ii) a expansão do Canal do Panamá, permitindo a travessia de navios maiores entre os Oceanos Atlântico e Pacífico; (iii) a maior conteinerizacão das cargas, que facilita os desafios de logística e armazenagem; e, (iv) a forte competição no mercado oligopolista de transporte de longo curso, cujo faturamento anual equivale a 5\% do PIB global. Assim, dado que existe uma vantagem competitiva nas economias de escala dos navios, a concorrência no mercado de transporte de longo curso estaria alimentando a tendência de aumento das proporções e a consequente redução dos preços de frete - ver as matérias "Economies of scale made steel" (12/11/2011) e "The big-box game" (31/10/2015) na revista The Economist. 
mesmo em fins de semana, como trabalham os navios; e, (iii) as limitações físicas e estruturais que dificultam a atracação dos navios - ausência de manutenção regular da profundidade dos canais de navegação, controle inadequado do trânsito marítimo, pouca disponibilidade e agilidade dos práticos e rebocadores no atendimento ao navio etc. ${ }^{2}$

Quanto ao último grupo de problemas, devido à falta de dragagem regular dos acessos aquaviários, é comum haver um grande acúmulo de sedimentos no fundo das hidrovias e, consequentemente, há um aumento do risco de choque dos cascos dos navios e uma restrição ao calado das embarcações - o que gera aumento dos preços de seguro marítimos em operações no Brasil (CODESP 2009). Em última instância, com frequência é preciso esperar a maré subir para manobrar com segurança, o que também gera custos de demurrage - decorrentes da extrapolação do tempo de uso de equipamentos e serviços (IPEA 2010). Portanto, as limitações nos acessos aquaviários nacionais aumentam os custos de frete e logística porque, ao mesmo tempo, geram maiores custos de seguro e demurrage e impedem que o país participe das rotas dos grandes navios modernos - de preços mais competitivos no transporte global.

Para mitigar esses problemas e favorecer uma redução dos custos de frete e logística no Brasil, foi executado, entre 2007 e 2013, o Programa Nacional de Dragagem (PND) - ao custo de R\$ 1,1 bilhão, financiado pelo governo federal. Nesse contexto, o artigo busca contribuir com a literatura nacional que analisa a problemática dos portos ao conduzir uma análise de resultados desse programa - e gerar subsídios para o seu aprimoramento. Todavia, como não existem informações com especificidade suficiente para analisar a eventual contribuição do PND na redução direta dos custos de frete e logística, o objetivo específico da pesquisa se restringirá ao teste da hipótese de que o programa possibilitou uma maior e mais rápida movimentação de carga por navio e porto - o que guardaria uma correspondência com o aumento de eficiência, redução dos custos de transporte e a possibilidade de se receber navios de maiores dimensões.

Para testar essa hipótese, faz-se uso de uma base de microdados ainda pouco explorada, fornecida pela Secretaria de Portos da Presidência da República (SEP) e pela Agência Nacional de Transportes Aquaviários

2 Detalhes sobre essa problemática podem ser vistos em Akabane e Gonçalves (2008), Campos Neto et al. (2009), Cortez et al. (2013), Marchetti e Ferreira (2014), Menegazzo e Fachinello (2014), Carvalho et al. (2015) e Britto et al (2015). 
(ANTAQ), que contém informações mensais, entre 2010 e 2014, da movimentação de carga por navio e características dos portos e das embarcações. Para lidar com o fato de que cada porto recebeu uma intervenção diferente do outro (em termos de tempo e forma de dragagem, exposição de condições climáticas e regime de marés, embargo de obras, problemas com licitações e licenças ambientais etc.), recorreu-se à metodologia dos controles sintéticos (Abadie e Gardeazabal 2003; Abadie et al., 2010, 2011, 2015).

Dessa forma, em 11 portos analisados, tendo 24 instalações comparativas, encontraram-se indicativos que o PND melhorou a eficiência da movimentação de carga em quatro portos: Aratu (BA), passando de uma média de $11,5 \mathrm{mil} \mathrm{t} /$ navio para $12,3 \mathrm{mil} \mathrm{t} /$ navio (aumento de 7,0\% em relação ao contrafactual estimado pelo controle sintético); (ii) Fortaleza (CE), de 11,2 mil t/navio para 12,3 mil t/navio (9,8\%); (iii) Rio Grande (RS), de 9,5 mil t/navio para 10,5 mil t/navio (10,5\%); e, (iv) São Francisco do Sul (SC), de 15,8 mil t/navio para 19,8 mil t/navio (25,3\%). Assim, a principal conclusão que será apresentada é que o programa precisa ser aprimorado para galgar resultados mais efetivos, mas não pode ser abandonado porque é estratégico para se reduzir os custos de frete e logística e melhorar a inserção do Brasil no comércio internacional - o que corrobora com as conclusões de TCU (2014).

Além desta introdução, o artigo conta com mais cinco seções. A seção 2 contextualiza o PND. A seção 3 discute a estratégia de avaliação. A seção 4 apresenta a base de dados. A seção 5 mostra os resultados encontrados. Por fim, na seção 6 têm-se as conclusões.

\section{Contextualização do PND}

Conforme definido na chamada "Lei dos Portos" (Lei 12.815, de 5 de junho de 2013), as dragagens são obras ou serviços de engenharia relacionados à desobstrução, remoção, derrocamento ou escavação de material do fundo de rios, lagos, mares, baías e canais. A finalidade dessas obras é aumentar a profundidade dos acessos aquaviários, permitindo que navios de maior porte e calado possam acessar as unidades portuárias sem riscos de choques nos cascos. Por consequência, as dragagens permitem uma 
maior movimentação de cargas por navio, e assim é possível obter economias de escala e redução de custos de frete e seguro marítimo - em última instância, isto favorece as atividades de logística nacional e internacional.

Até a década de 1960, as atividades de dragagem no Brasil eram feitas por empresas estrangeiras especializadas, contratadas pelas próprias autoridades portuárias (Campos Neto et al. 2009; Fadda 2012). Sendo que durante o regime militar tais atividades foram consideradas estratégicas para o país, culminando na intervenção federal nos processos de planejamento a execução das obras - nessa linha de raciocínio, nos Estados Unidos e na Inglaterra, por exemplo, a maioria das obras de dragagem são conduzidas por divisões militares desde o fim do Século XIX. Considerando isso, em 1967 foi criada a Companhia Brasileira de Dragagem (CBD) e foram realizadas aquisições de dragas (de fabricação estrangeira), a fim de atender as necessidades dos portos nacionais. Em 1993, a CBD foi extinta, e a responsabilidade das obras de dragagem foi transferida novamente para as administradoras das instalações portuárias - as Companhias Docas na maioria dos casos. Nesse movimento, devido à falta de recursos financeiros e equipamentos apropriados, as autoridades portuárias tiveram dificuldades em fazer a manutenção da profundidade dos canais de acesso. Assim, considerando os altos custos de demurrage que passaram a ser observados desde o fim da década de 1990, por consequência da falta de dragagens regulares, em 2007 o PND foi instituído para operacionalizar as obras nas instalações públicas, passando a ser uma competência da SEP.

A primeira fase de intervenções ocorreu entre 2009 e 2013, com 13 projetos efetivados, totalizando $\mathrm{R} \$ 1,1$ bilhão em investimentos. A Tabela 1 lista os projetos efetivados, os valores investidos, a profundidade dos canais antes e depois da dragagem, o volume de sedimentos retirados e o mês de término da intervenção - que se deu em função da complexidade de cada caso em termos de desafios de engenharia e financiamento. Além dos portos ali listados, em Cabedelo (PB) e Vitória (ES), algumas intervenções chegaram a ser iniciadas, mas foram interrompidas pelos mais diversos motivos, e não haviam sido efetivadas até a finalização da pesquisa.

A única avaliação encontrada do PND foi promovida pelo Tribunal de Contas da União (TCU 2014) - e é parte integrante do processo TC 009.504/2013-3 -, cujas conclusões apontam que não há indícios de melhora no sistema de atracação e movimentação de cargas que possa ser atribuída ao programa, e que possivelmente isso estaria relacionado com 
dois fatos. Primeiro, apesar do aprofundamento nos canais, os berços de atracação podem não ter sido devidamente adequados para as novas profundidades. Segundo, possivelmente as sinalizações também não foram adequadas, o que estaria gerando dificuldades para a utilização plena das vias dragadas. A despeito disso, no fim de 2014 foi lançada uma segunda fase do PND, orçada em R \$ 4,7 bilhões para a adequação das obras em Santos, Suape, Rio Grande e Rio de Janeiro, e a inclusão do porto de Paranaguá - os processos de licitação dessa fase ainda estavam em andamento até a finalização dessa pesquisa.

Tabela 1 - Investimento, profundidade dos canais, volume de sedimentos retirados e mês de término das obras nos projetos efetivados pelo PND.

\begin{tabular}{|c|c|c|c|c|c|c|}
\hline Porto & Estado & $\begin{array}{l}\text { Investimento (R\$ } \\
\text { milhões) }\end{array}$ & $\begin{array}{l}\text { Profun } \\
\text { Antes }\end{array}$ & $\begin{array}{l}\text { ade }(\mathrm{m}) \text { : } \\
\text { Depois }\end{array}$ & $\begin{array}{l}\text { Volume retirado } \\
\text { (milhões de m3) }\end{array}$ & $\begin{array}{l}\text { Término } \\
\text { da obra }\end{array}$ \\
\hline Angra dos Reis & RJ & 2,8 & 9,5 & 10 & 0,1 & $\mathrm{jul} / 10$ \\
\hline Aratu & BA & 41,2 & 12 & 15 & 2,9 & fev/11 \\
\hline Fortaleza & CE & 52,5 & 11 & 14 & 6,0 & $\mathrm{jul} / 13$ \\
\hline Itaguaí & RJ & 80,3 & 14,5 & 17,5 & 4,7 & $a b r / 11$ \\
\hline Itajaí & SC & 68,9 & 11 & 14 & 6,3 & $\mathrm{jan} / 12$ \\
\hline Natal & $\mathrm{RN}$ & 33,5 & 10 & 12,5 & 1,8 & ago/12 \\
\hline Recife & PE & 27,5 & 8,5 & 11,5 & 2,8 & $\mathrm{mai} / 10$ \\
\hline Rio de Janeiro & RJ & 138,2 & 9,5 & 15 & 4,0 & out $/ 11$ \\
\hline Rio Grande & RS & 201,7 & 13 & 18 & 22,2 & jun/12 \\
\hline Salvador & BA & 57,7 & 9 & 15 & 1,6 & fev/11 \\
\hline Santos & $\mathrm{SP}$ & 211,9 & 13 & 15 & 17,8 & $\operatorname{dez} / 13$ \\
\hline São Frco do Sul & SC & 102,0 & 12 & 14 & 4,4 & $\mathrm{fev} / 12$ \\
\hline Suape & PE & 73,0 & 11 & 15,5 & 3,3 & $\mathrm{mai} / 11$ \\
\hline
\end{tabular}

Fonte dos dados: SEP. Elaboração própria.

Todavia, no trabalho do TCU foram usadas metodologias de auditoria operacional que não partiram do arcabouço de Neyman-Rubin - também conhecido por "modelo de resultados potenciais". Sendo que tal modelo tem se tornado a pedra angular da avaliação de políticas públicas nos últimos anos, como é discutido em Khandker et al. (2010), Gertler et al. (2016) e Athey e Imbens (2016). A razão disso é o consenso na literatura acadêmica de que a maneira mais adequada de se estimar as relações causais de qualquer intervenção, no sentido de reduzir vieses de avaliação, é através da comparação adequada com um grupo de controle - i.e., nesse caso, um conjunto de portos que não recebeu a intervenção. 


\section{Estratégia de Avaliação: o controle sintético}

Seguindo o protótipo de Rubin (2005), o primeiro passo da estratégia de avaliação é considerar a existência de várias instalações portuárias passíveis de comparação - de fato, há 235 portos públicos, terminais de uso privado e estações de transbordo na listagem operacional da ANTAQ - e apenas parte delas participou do PND. Complementarmente, para cada instalação $j$ a efetividade do programa pode se refletir em algum indicador $Y_{j}$, de forma que toda instalação possui um resultado potencial antagônico ao $Y_{j}$ observado, dado que recebeu ou não a intervenção do PND, o que é denominado de "contrafactual", e é impossível de ser observado (consequentemente impossível de determinar precisamente o impacto do programa em cada unidade de intervenção).

A despeito disso, um impacto médio das intervenções poderia ser estimado sem viés em um teste de diferenças de medias de $Y_{j}$ entre os grupos de tratamento (i.e., que receberam a intervenção) e de controle, desde que: (i) o grupo de tratamento fosse escolhido aleatoriamente; (ii) a intervenção fosse homogênea; e, (iii) o fato de uma instalação $j$ ser tratada não interferisse no resultado potencial de $j^{\prime} \neq j$. Todavia, é certo que nada disso se passou com o PND, já que a escolha dos portos tratados não foi aleatória e, portanto, o tratamento não foi homogêneo e tampouco é razoável imaginar que a intervenção em um porto não afeta os resultados de outro - detalhes em Carvalho et al. (2015).

Alternativamente, Khandker et al. (2010), Gertler et al. (2016) e Athey e Imbens (2016), entre outros autores, listam outras estratégias de estimação de impacto dentro do arcabouço de Neyman-Rubin, possíveis de serem implementadas, dependendo de como o programa foi executado e do tipo de dados que se dispõe. Quanto a esse último ponto, a ANTAQ forneceu um painel de microdados contendo informações mensais da movimentação de navios, cargas e covariadas nas instalações portuárias brasileiras. No contexto, já que o objetivo mor do PND é gerar eficiência no processo de atracação e carregamento/descarregamento - e assim permitir a redução dos custos relacionados com frete e logística -, a média mensal da movimentação de carga por navio atracado se mostra um adequado indicador de impacto. Pois se esta variável aumenta, significa que se está ganhando eficiência no sistema - de fato, o indicador é uma extrapolação do conceito naval de "prancha média", dado pelas toneladas movimentadas por navios por hora de operação (SEP 2015). 
Outros indicadores de impacto tiveram seu uso considerado para esta pesquisa, mas foram posteriormente descartados. Por exemplo, o tempo de inoperância antes da atracação, que é definido pela diferença entre os marcos temporais da chegada do navio nas proximidades do porto (ou na área de fundeio) e da efetiva atracação, em um primeiro momento pode parecer um bom candidato a indicador de impacto do PND. Todavia, como o momento da atracação depende de uma miríade de fatores não observáveis (existência de espera para atracar, comprimento do canal de navegação, trânsito no canal de acesso, regime de marés, disponibilidade e agilidade dos práticos e rebocadores no atendimento ao navio, agilidade de órgãos anuentes ao liberar a atracação do navio, fatores climáticos, eventuais falhas dos equipamentos, esperas propositais dos armadores etc.), uma análise considerando essa variável objetivo poderia alcançar resultados contaminados por fatores alheios ao objetivo da pesquisa - por isso esse indicador de impacto foi descartado.

Outro exemplo de indicador de impacto pouco adequado seria o tempo de operação, definido pela diferença entre os marcos temporais de início e término do carregamento/descarregamento do navio. Já que, ceteris paribus, se o programa gerar impacto, ocorrerá uma maior consignação de carga, o que levaria a um maior tempo de operação. Desta forma, supondo que as obras de dragagem permitem que navios carreguem/descarreguem maior quantidade de carga, consequentemente, ocorreria um maior tempo de operação. Logo, apesar da potencial importância de monitoramento do tempo de operação, este indicador não reflete os benefícios das obras de dragagem em um determinado porto. Sendo, portanto, preferíveis indicadores relacionados à movimentação de carga, que permitem uma compreensão mais direta dos potenciais benefícios das intervenções - em especial, uma variação do conceito de prancha média.

Dito isso, e tendo definido o indicador de impacto como a média mensal da movimentação de carga por navio atracado, com essa base de dados é possível se considerar um protocolo de "diferenças-em-diferenças" (Khandker et al. 2010; Gertler et al. 2016; Athey e Imbens 2016). Assim, o modelo de avaliação assumiria uma forma $Y_{j t}=\delta_{t}+Z_{j t}+u_{j t}$, em que $Y_{j t}$ é o volume médio de carga movimentada por navio na instalação $j$ e mês $t, \delta_{t}$ é um fator de trajetória (representando tendências e sazonalidades), $Z_{j t}$ é um fator de covariadas observada (e.g., o percentual de graneleiros de sólidos atracados no mês vis-à-vis outra categoria de navio, já que estes costumam movimentar muita carga em uma única escala) e $u_{i j t}$ representa covariadas 
não observadas (ou omitidas) e outros erros . Nesse protocolo, a principal hipótese de identificação do impacto do programa é que a trajetória contrafactual média das unidades tratadas seguiria de forma paralela com a trajetória média do grupo de controle - a Figura 1[a] ilustra isso.

$\mathrm{Na}$ ilustração têm-se seis instalações observadas, onde duas formam o grupo de tratamento (quadrado e círculo preto) e quatro formam o grupo de controle (quadrado, círculo, triângulo e losango branco), em três pontos do tempo, sendo que a intervenção ocorre entre o primeiro e o segundo. O eixo vertical guia a marcação dos hipotéticos valores observados para $Y_{j t}$ condicionado por $Z_{j t}$. Em conjunto, esses elementos são suficientes para representar a ideia geral das diferenças-em-diferenças, qual seja, as linhas cinza e preta são as trajetórias médias do controle e do tratamento, respectivamente. Já a linha tracejada é a trajetória paralela com a média do controle partindo da média inicial do tratamento. Então a distância entre as linhas preta e tracejada seria uma estimativa de impacto médio do programa.

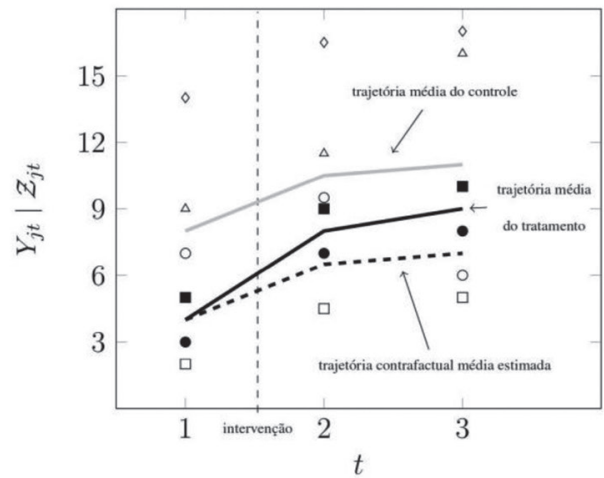

[a] diferenças-em-diferenças

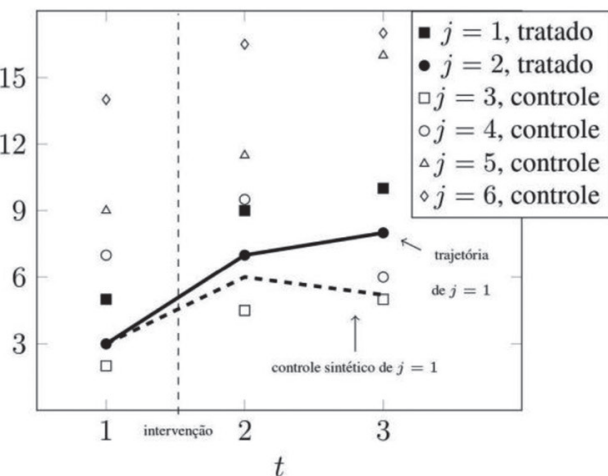

[b] controle sintético

Figura 1 - Ilustração das estimativas de impacto feitas através de diferenças-em-diferenças e controle sintético. Elaboração própria.

Todavia, como já salientado, o PND promoveu tratamentos diferentes entre os portos, pois cada caso teve suas peculiaridades - i.e., a profundidade, o volume de sedimentos retirados e o tempo de duração das obras foram diferentes entre os casos, vide Tabela 1. Apesar disso não impedir a implementação das diferenças-em-diferenças gera dificuldades de ope- 
racionalização, uma vez que muitas variáveis de controle teriam de ser inseridas no protótipo, e o modelo poderia se tornar demasiadamente intricado. Em contraponto, com a base de dados disponibilizada pela ANTAQ, também é possível implementar a metodologia do "controle sintético". 3

Inicialmente proposto por Abadie e Gardeazabal (2003) para análise de séries macroeconômicas dentro do arcabouço de Neyman-Rubin, com posteriores aprimoramentos em Abadie et al. (2010, 2011, 2015), a principal hipótese de identificação do impacto nos controles sintéticos é que a trajetória contrafactual de uma particular unidade tratada seguiria uma combinação convexa da trajetória das unidades do controle - a Figura $1[\mathrm{~b}]$ ilustra isso. Ali a trajetória de $j=1$, círculo preto, é comparada com uma combinação linear de pesos 0,8 e 0,2 das trajetórias das unidades $j=3$ e $j=4$, quadrado e círculo branco, respectivamente - estes dois são chamados de "doadores".

Se o desafio nas diferenças-em-diferenças é estruturar e estimar adequadamente os parâmetros de uma equação linear que descreve trajetórias médias, o desafio no controle sintético é calibrar adequadamente os pesos de uma combinação convexa das trajetórias observadas no grupo de controle. Para tanto, considerando esse último, sem perda de generalidade, o raciocínio começa por definir $j=1$ como o caso de interesse e $j=2, \ldots$, $J+1$ como os potenciais doadores - i.e., há $J$ unidades no grupo de controle. Em seguida, define-se $\left\{\mathrm{Y}_{\mathrm{jt}}^{1}\right\}_{\mathrm{t}=1}^{\mathrm{T}}$ como a trajetória com a intervenção e $\left\{\mathrm{Y}_{\mathrm{jt}}^{0}\right\}_{\mathrm{t}=1}^{\mathrm{T}}$ como a trajetória no caso contrário, assumindo que a intervenção não tem efeito até um determinado momento $\tau$, i.e., $\mathrm{Y}_{\mathrm{jt}}^{1}=\mathrm{Y}_{\mathrm{jt}}^{0} \mathrm{se} t \leq \tau<T$. Assim, ocorre que $\mathrm{Y}_{\mathrm{jt}}=\mathrm{Y}_{\mathrm{jt}}^{0}+1_{(\mathrm{se} i=1)} \Delta_{t}$ se $t>\tau$, em que 1 é uma função indicadora e $\Delta_{t}$ é o efeito da intervenção na trajetória da unidade tratada. Além disso, considera-se:

$$
Y_{j t}=\delta_{t}+\theta_{t} Z_{t}+\lambda_{t} \mu_{j}+\varepsilon_{j t}
$$

onde $Y_{j t}$ e $\delta_{t}$ seguem as definições já estabelecidas; $\theta_{t}$ é um vetor $1 \times K$ e $Z_{t}$ é um vetor $K \times 1$ de covariadas, tal que $z_{j t}=\theta_{t} Z_{i} ; \lambda_{\mathrm{t}}$ e $\mu_{\mathrm{j}}$ são, respectivamente, vetores linha e coluna compatíveis, cujo produto representa um fator de

3 Detalhes sobre eventuais dificuldades de operacionalização das diferenças-em-diferenças podem ser vistos em Robins et al. (2015). Esses autores analisam uma política antidrogas nos Estados Unidos, que guarda semelhança com os múltiplos tratamentos do PND, e, assim como aqui, os controles sintéticos são usados como alternativa. 
covariadas não observadas (ou omitidas); $\varepsilon_{\mathrm{jt}}$ é um fator de erro com média zero; e a soma $\lambda_{t} \mu_{j}+\varepsilon_{j t}$ é igual ao fator $u_{i t}$ definido anteriormente.

O passo seguinte é considerar um vetor de pesos $W$ de dimensão $J \times 1$, tal que $w_{j} \geq 0$ para todo $w_{j} \in \mathrm{W}, j=2, \ldots, J+1$, e $\sum_{j=2}^{J+1} w_{j}=1$. Assim, partindo da Equação (1) Abadie et al. (2010) mostram que se $\Lambda=\sum_{t=1}^{\tau} \lambda_{t}^{\prime} \lambda_{t}$ é não singular e se existe $\mathrm{W}^{*}$ tal que $\mathrm{Y}_{1 \mathrm{t}}=\sum_{j=2}^{J+1} w_{j}^{*} Y_{j t}$ para $\mathrm{t} \leq \tau$ e $Z_{1}=\sum_{j=2}^{J+1} w_{j}^{*} Z_{j}$, então o seguinte resultado pode ser encontrado:

$Y_{1 t}-\sum_{j=2}^{J+1} w_{j}^{*} Y_{j t}=\sum_{j=2}^{J+1} w_{j}^{*} \sum_{i=1}^{\tau} \lambda_{i} \Lambda^{-1} \lambda_{i}^{\prime}\left(\varepsilon_{j i}-\varepsilon_{1 i}\right)-\sum_{j=2}^{J+1} w_{j}^{*}\left(\varepsilon_{j t}-\varepsilon_{1 t}\right)$

Como o lado direito da igualdade (2) são médias ponderadas de combinações lineares de fatores de erro com média zero, um estimador não viesado para o efeito da intervenção na trajetória da unidade tratada seria $\hat{\Delta}_{t}=Y_{1 t}-\sum_{j=2}^{J+1} w_{j}^{*} Y_{j t}$ dadas as hipóteses do modelo. Entretanto, como mostram Abadie et al. (2010), só em casos muito particulares a igualdade (2) se mostrará com precisão. Assim, o desafio passa a ser a calibragem de um vetor aproximado para $\mathrm{W}^{*}$ - sendo que Abadie et al. $(2010,2011,2015)$ apresentam algumas possibilidades. Dentre essas, nessa pesquisa o vetor de pesos considerado aproximado, $\widehat{W}^{*}$, será determinado da seguinte forma:

$$
\begin{gathered}
\widehat{W}^{*}=\operatorname{argmin}|| \mathrm{X}_{1}-\mathrm{X}_{0} \mathrm{~W} \| \\
\text { s.r. }: w_{j} \geq 0 \text { para todo } w_{j} \in \mathrm{W} \\
\sum_{j=2}^{J+1} w_{j}=1
\end{gathered}
$$

onde: ||.|| é a norma Euclidiana;

$$
\mathrm{X}_{1}=\left[\begin{array}{c}
\bar{Y}_{1} \\
Z_{1}
\end{array}\right] ; \mathrm{X}_{0}=\left[\begin{array}{ccc}
\bar{Y}_{2} & \ldots & \bar{Y}_{J+1} \\
Z_{2} & \ldots & Z_{J+1}
\end{array}\right] ; \mathrm{e}, \bar{Y}_{J}=\frac{\sum_{i=1}^{\tau} Y_{j t}}{\tau}
$$

A estrutura (3) descreve que os pesos escolhidos serão aqueles que minimizam a distância métrica entre dois pontos do $\mathbb{R}^{1+K}$, quais sejam: o formado pela média aritmética da trajetória do indicador de impacto ${ }^{4} \mathrm{e}$

${ }^{4}$ Note que se $Y_{1 t}=\sum_{j=2}^{J+1} w_{j}^{*} Y_{j t}$, como se pressupõe ao alcançar o resultado (2), então $\bar{Y}_{1 t}=\sum_{j=2}^{J+1} w_{j}^{*} \bar{Y}_{j t}$. 
pelas $K$ covariadas da unidade tratada $\left(\mathrm{X}_{1}\right)$; e, o formado pela combinação convexa dos $J$ pontos equivalentes para as unidades de controle $\left(\mathrm{X}_{0} \mathrm{~W}\right)$. $\mathrm{O}$ que nada mais é do que uma generalização da ideia esboçada anteriormente na Figura $1[\mathrm{~b}]$ - na terminologia dos controles sintéticos, $\mathrm{X}_{1}$ e $\mathrm{X}_{0}$ são denominados de "matrizes de predição" ou, simplesmente, preditores.

Dois pontos ainda merecem atenção em relação à metodologia. Primeiro, uma nova profundidade precisa ser homologada pela Marinha ao término das obras de dragagem, e só assim o seguro dos navios cobre algum tipo de acidente ocorrido na atracação. Nesse sentido, é razoável considerar $\tau$ como as datas de término das obras. Segundo, para se testar a adequação dos pesos, Abadie et al. $(2010,2011,2015)$ propõem a resolução e comparação de problemas de validação cruzada, que podem ser feitos da seguinte forma: apenas parte dos elementos de $\widehat{W}^{*}$ serão diferentes de zero; assim, ao retirar sequencialmente todo doador $j$ com peso diferente de zero e reestimar (3) - os resultados das soluções sequenciais gerará uma referência para se inferir a variância do controle sintético.

\section{Análise Descritiva dos Dados}

Como exposto anteriormente, os dados fornecidos pela SEP e pela ANTAQ tratam das características dos portos e dos navios, especialmente da movimentação de carga, tendo frequência mensal entre fevereiro de 2010 e agosto de 2014. Nesse sentido, quatro participantes do programa não serão analisados: Angra dos Reis, já que em 84,2\% dos meses observados este porto não recebeu ou recebeu apenas um navio de carga; Cabedelo e Vitória, já que receberam intervenções parciais e incompletas até o último mês observado - ou seja, potenciais resultados observados nesses casos não refletiriam a efetividade do programa; e, Recife, já que suas obras foram concluídas em maio de 2010, e, portanto, haveria poucas observações para se atribuir algum eventual impacto ao programa. 
Tabela 2 - Médias da movimentação mensal por navio, em mil t, antes e depois da intervenção no respectivo porto - observações compreendidas no período entre fevereiro de 2010 e agosto de 2014.

\begin{tabular}{l|c|cc|c}
\hline \multirow{2}{*}{ Porto } & \multirow{2}{*}{ Estado } & \multicolumn{2}{|c|}{ Movimentação } & \multirow{2}{*}{ Diferença Depois-Antes } \\
\hline Aratu & BA & 10,51 & 11,82 & $1,31{ }^{*}$ \\
Fortaleza & CE & 8,44 & 12,26 & $3,82^{*}$ \\
Itaguaí & RJ & 51,50 & 61,58 & $10,08{ }^{*}$ \\
Itajaí & SC & 6,49 & 8,22 & $1,73^{*}$ \\
Natal & RN & 4,32 & 5,95 & $1,63^{*}$ \\
Rio de Janeiro & RJ & 4,58 & 5,27 & $0,69^{*}$ \\
Rio Grande & RS & 7,33 & 10,07 & $2,74^{*}$ \\
Salvador & BA & 3,77 & 4,21 & $0,44^{*}$ \\
Santos & SP & 17,61 & 20,28 & $2,67{ }^{*}$ \\
São Francisco do Sul & SC & 13,92 & 21,40 & $7,48^{*}$ \\
Suape & PE & 17,61 & 20,28 & $2,67^{*}$ \\
\hline
\end{tabular}

* Indica significância estatística com 95\% de confiança.

Elaboração própria.

A Tabela 2 apresenta uma simples comparação da média do indicador de impacto - i.e., a movimentação mensal de carga por navio, em mil toneladas - antes e depois da intervenção. Como foi discutido anteriormente - e é exaustivamente detalhado em Khandker et al. (2010) e Gertler et al. (2016), entre outros autores -, esta comparação não pode fundamentar a análise dos resultados do programa porque não reflete as situações contrafactuais, mas é útil para evidenciar pelo menos dois pontos: as médias aumentaram depois da intervenção em todas as unidades observadas onde houve obras do PND; e, o impacto causado pelo programa pode ter magnitude consideravelmente diferente entre as unidades de intervenção - ambos os pontos tornam clara a necessidade de grupos de controle adequados para cada unidade tratada.

A fim de encontrar controles adequados, inicialmente tabulou-se as informações para todas as 235 instalações portuárias brasileiras, mas verificouse a inexistência de movimentação por meses subsequentes e/ou características altamente específicas em 197 delas. ${ }^{5}$ Dessa forma, a análise focará

5 Exemplos de instalações bastante movimentadas, mas altamente especializadas, são os terminais da Petrobras: Almirante Barroso (SP), Almirante Maximiano da Fonseca (RJ), Almirante Soares Dutra (RS), Almirante Tamandaré (RJ), Guamaré (RN), TUP Manaus (AM), Madre de Deus (BA) e TUP SFS (SC); da Vale: Praia Mole (ES), Tubarão (ES), Guaíba (RS) e Ponta da Madeira (MA); da Samarco: Ponta do Ubu (ES); e, da MNR Mineração: Trombetas (PA). 
11 unidades tratadas e 24 de controle; destas, oito são portos públicos e 16 são instalações privadas - no Apêndice 1 essa listagem é detalhada.

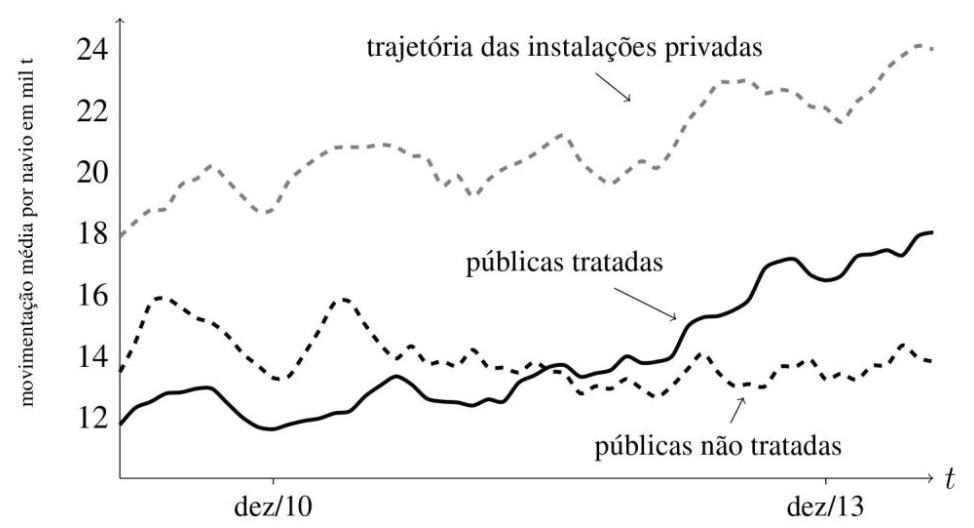

Figura 2 - Trajetórias da movimentação mensal por navio em instalações portuárias privadas e públicas tratadas e não tratadas. Fonte dos dados: SEP e ANTAQ. Elaboração própria.

Assim, mais do que a observação de que as médias aumentaram depois da intervenção em todas as unidades tratadas e observadas, na Figura 2 ilustram-se as trajetórias da movimentação mensal por navio em instalações portuárias privadas e públicas tratadas e não tratadas, e então é possível notar uma trajetória ascendente - e um patamar mais alto - do indicador de impacto quando medido entre as unidades privadas, e descendente - e um patamar mais baixo - quando medido nas unidades públicas não tratadas. Enquanto as trajetórias nas unidades privadas e nas tratadas pelo PND indicam a existência de um aumento de movimentação de cargas por navio nos portos brasileiros no período em tela, o segundo indica um possível movimento de migração de uso entre os portos públicos - na direção de aumento de procura pelas unidades tratadas pelo PND - o que está alinhado com a análise de Carvalho et al.(2015).

As diferentes trajetórias e patamares são essencialmente devidas às características do porto e dos navios que lá atracam. Por exemplo, Aratu é especializado na movimentação de combustíveis e gases liquefeitos, portanto, recebe muitos graneleiros de líquidos; Itaguaí movimenta grandes volumes de minério, portanto, recebe graneleiros de sólidos de maiores calados; Itajaí é especializado em conteinerizacão, portanto, recebe praticamente 
só conteineiros; e Rio Grande é um porto especializado no escoamento de safras agrícolas - e isso tudo se reflete no volume de carga movimentado em cada instalação. Portanto, fica evidente que cada porto precisa ser comparado com outros portos similares - ou o mais similar possível de ser observado -, a fim de controlarem-se adequadamente os efeitos de outros fatores sobre o indicador de impacto que não são os relacionados com as intervenções do PND. Isto, aliado ao fato que a intervenção foi diferente em cada porto (em termos de tempo e forma de dragagem, exposição de condições climáticas e regime de marés, embargo de obras, problemas com licitações e licenças ambientais etc.), explicita a importância da metodologia do controle sintético para essa pesquisa.

Tabela 3 - Médias entre fev/10-ago/14 e desvios padrão (em parênteses), por instalações tratadas, públicas não tratadas e privadas, do número de navios atracados, movimentação, DTW e calado dos navios, e percentuais deles em navegação de longo curso, com bandeira brasileira e especialidade de carregamento.

\begin{tabular}{|c|c|c|c|c|c|c|c|c|c|c|}
\hline Instalações & 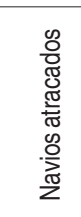 & 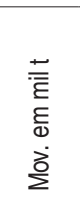 & 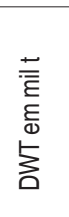 & 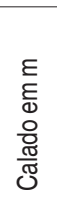 & 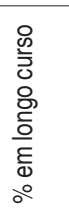 & 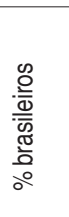 & 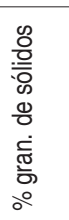 & 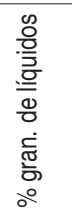 & 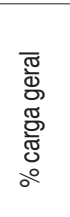 & 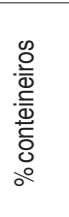 \\
\hline \multirow{2}{*}{ Tratadas } & 106,6 & 14,0 & 44,4 & 9,3 & 65,1 & 14,3 & 14,9 & 12,3 & 7,9 & 57,5 \\
\hline & $(109,7)$ & $(15,3)$ & $(17,7)$ & $(1,1)$ & $(11,1)$ & $(9,0)$ & $(12,5)$ & $(17,3)$ & $(5,5)$ & $(25,6)$ \\
\hline \multirow{2}{*}{ Públicas (não tratadas) } & 47,2 & 13,9 & 35,5 & 8,5 & 67,9 & 8,6 & 33,9 & 19,2 & 17,8 & 18,0 \\
\hline & $(59,0)$ & $(6,7)$ & $(8,6)$ & $(0,7)$ & $(20,2)$ & $(7,7)$ & $(21,7)$ & $(18,8)$ & $(19,4)$ & $(19,7)$ \\
\hline \multirow{2}{*}{ Privadas } & 18,9 & 20,8 & 38,2 & 8,7 & 75,3 & 13,7 & 35,1 & 20,6 & 16,2 & 22,5 \\
\hline & $(17,9)$ & $(12,6)$ & $(11,6)$ & $(0,9)$ & $(20,6)$ & $(17,6)$ & $(35,1)$ & $(37,4)$ & $(23,2)$ & $(39,7)$ \\
\hline
\end{tabular}

Fonte dos dados: ANTAQ.

Elaboração própria.

A fim de gerar uma caracterização adequada de cada porto para sintetizar a trajetória do indicador de impacto nos portos tratados, a Tabela 3 apresenta médias e desvios padrão das variáveis observadas na base de dados, considerando todas as unidades tratadas, públicas não tratadas e privadas em todo período em tela. Na primeira coluna, note que a média mensal do número de navios atracados nas instalações tratadas foi de 106,6; nas públicas não tratadas foi de 47,2, e nas privadas foi de 18,9. No Apêndice 
1, essas estatísticas são replicadas para cada instalação, em que é possível notar que o valor das unidades tratadas é puxado para cima pelo porto de Santos, o maior do país, que recebeu uma média de 422,2 navios por mês.

Em relação ao indicador de impacto ora analisado, note que as instalações públicas, tratadas e não tratadas, movimentaram cerca de 14 mil toneladas por navio ao mês no período em tela, enquanto a média das instalações privadas foi de 20,8 mil toneladas por navio ao mês. Uma explicação para a maior movimentação média nas instalações privadas poderia derivar do fato de que elas recebem menos navios de contêineres, que são mais frequentes nos portos tratados, e que este tipo de navio costuma fazer mais escalas que os outros tipos. Nesse sentido, é importante ressaltar que o termo "movimentação" diz respeito ao lote que está em consignação, indicando a soma de quanto o navio carregou e descarregou em determinado porto, e não o quanto está efetivamente embarcado - afinal, em cada escala um navio pode carregar ou descarregar apenas parte da sua carga.

Já em relação às covariadas, as informações disponíveis dizem respeito às médias mensais dos seguintes indicadores por navio atracado em cada instalação: capacidade de carga, mensurada em mil toneladas DWT; calado de projeto da embarcação, mensurado em metros - este dado não se refere ao calado que o navio entrou ou saiu do porto, mas ao máximo possível para navegação com segurança; se o navio está em rota de longo curso - no caso contrário ele está em cabotagem; se possui bandeira brasileira; e, se sua classificação se encaixa entre as quatro principais - graneleiros de sólidos ou líquidos, transporte de carga geral e conteineiros. ${ }^{6}$

Na Tabela 3 nota-se que a capacidade média de carga dos navios atracados é o dobro ou mais da média de carga movimentada, e que as instalações tratadas costumam receber navios maiores que as de controle - o que também se reflete na média mais alta dos calados de projeto. Em média, mais de $2 / 3$ dos navios atracados estão em navegação de longo curso, o que reflete o fato de os portos serem o principal modal para o comércio exterior, sendo que uma minoria das embarcações possui bandeira brasileira.

${ }_{6}$ O leitor interessado em detalhamentos dessas variáveis pode consultar, por exemplo, Rodrigues (2008), CODESP (2009), Grammenos (2013), Levinson (2013) ou UNCTAD (2015). 
Como dito antes, também é possível observar que os portos tratados são mais frequentados pelos conteineiros - precisamente a classe de navios que mais cresce em dimensões, conforme é apresentado e discutido em Tran e Haasis (2015) - um reflexo do fato de que as instalações que mais movimentam contêineres no Brasil são Santos, Itajaí, Itaguaí, Rio de Janeiro e Salvador.

Outro ponto que pode ser observado é que, na média, as instalações públicas não tratadas e privadas possuem covariadas similares, respectivamente: 35,5 versus 38,2 mil toneladas na capacidade de carga; 8,5 versus 8,7 metros no calado; 67,9 versus $75,3 \%$ navios em navegação de longo curso; 8,6 versus $13,7 \%$ com bandeira brasileira; 33,9 versus $35,1 \%$ em graneleiros de sólidos; 19,2 versus 20,6\% em graneleiros de líquidos; 17,8 versus $16,2 \%$ em carga geral; e, 18,0 versus $22,5 \%$ em conteineiros. Por outro lado, os portos públicos não tratadas apresentam uma movimentação média de carga por navio de 13,9 mil toneladas, enquanto a média dos privados é de 20,8 mil toneladas. Ou seja, na média, essas instalações possuem características similares refletidas nas características das embarcações que recebem, mas as privadas são mais eficientes no indicador ora analisado, o que, possivelmente, decorre de uma melhor infraestrutura em terra.

\section{Resultados Estimados e Discussão}

A Tabela 4 apresenta os pesos do controle sintético resultantes da resolução do problema (3), onde nas linhas estão os portos tratados e nas colunas os doadores separados entre públicos e privados - as unidades do grupo de controle não listadas tiveram peso zero - por construção, os valores das linhas somam 1. Para a formação das matrizes de predição, $\mathrm{X}_{1}$ e $\mathrm{X}_{0}$, foram usadas as médias do indicador de impacto e das covariadas entre fevereiro de 2010, a primeira observação, e o mês da finalização das obras de dragagem - vide Tabela 1.

Note-se primeiro que nos casos dos portos de Itaguaí, Natal e Salvador houve apenas um doador suficientemente parecido em termos das covariadas observadas - i.e., houve peso exatamente 1 para o controle sintético de cada instalação. No caso de Itaguaí, o único porto suficientemente parecido para ter sua trajetória do indicador de impacto comparada é Alumar, o que decorre do fato que ambos são instalações bastante peculiares, que 
movimentam grandes cargas de minérios; já nos casos de Natal e Salvador, o único porto suficientemente parecido é Portonave, uma vez que as três instalações são encravadas em espaços urbanos e especializadas em conteinerizacão leve - o que também são características bem peculiares (TCU 2014; Carvalho et al. 2015). Consequentemente, esta pesquisa vai se restringir a grafar as trajetórias comparadas destes casos no Apêndice 2, explicitando que não é possível inferir sobre a hipótese de que o PND causou impacto nesses casos porque não há elementos para se chegar a conclusões suficientemente razoáveis.

Tabela 4 - Pesos no controle sintético, $\hat{\mathbf{W}}^{*}$, resultantes da resolução do problema (3).

\begin{tabular}{|c|c|c|c|c|c|c|c|c|c|c|c|c|c|c|c|c|c|}
\hline \multirow[b]{2}{*}{ Instalações } & \multicolumn{8}{|c|}{ Doadores Públicos } & \multicolumn{9}{|c|}{ Doadores Privados } \\
\hline & $\underset{\substack{\mathbb{E} \\
\mathbb{\Phi}}}{\frac{E}{\mathscr{W}}}$ & $\begin{array}{l}\text { 苋 } \\
\underline{\underline{\underline{D}}} \\
\underline{\underline{E}}\end{array}$ & 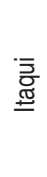 & 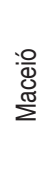 & 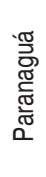 & 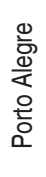 & 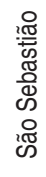 & 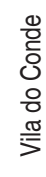 & 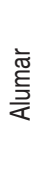 & 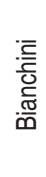 & 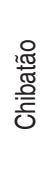 & 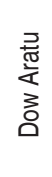 & 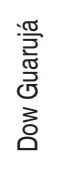 & 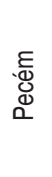 & 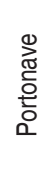 & 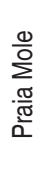 & 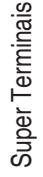 \\
\hline Aratu & & ,15 & & & & ,24 & & 10 & & & & ,50 & ,01 & & & & \\
\hline $\begin{array}{l}\text { Fortaleza } \\
\text { Itaguaí }\end{array}$ & 78 & & & & & ,07 & 03 & & 1 & & 12 & & & & & & \\
\hline Itajaí & & 10 & & & & & & & & & 11 & & & & 76 & & 03 \\
\hline Natal & & & & & & & & & & & & & & & 1 & & \\
\hline Rio de Janeiro & & & & & & 10 & & & & & & & & ,45 & ,45 & & \\
\hline Rio Grande & & ,36 & & & & & ,08 & & & & & & & & ,56 & & \\
\hline Salvador & & & & & & & & & & & & & & & 1 & & \\
\hline Santos & & & 25 & & ,55 & & ,06 & & & ,06 & & & & & 08 & & \\
\hline S. Frco do Sul & & 27 & & & & ,03 & ,05 & & & 22 & ,08 & & & & 19 & 04 & 12 \\
\hline Suape & 18 & & ,01 & ,04 & & & & & & & & & ,08 & ,37 & ,32 & & \\
\hline
\end{tabular}

Os demais resultados expostos na Tabela 4 geram casos onde não existe e onde existe evidência de que o PND aumentou a eficiência na movimentação de carga. De forma que pertencem ao primeiro tipo os portos de Itajaí, Rio de Janeiro, Santos e Suape - o que corrobora com TCU (2014), e cujos detalhes do controle sintético são apresentados no Apêndice 2 -, e pertencem ao segundo tipo os portos de Aratu, Fortaleza, Rio Grande e São Francisco do Sul.

No caso de Itajaí, à guisa de conjectura, considerando sua vizinhança com Portonave, é possível que este tenha tomado maior proveito das obras de dragagem do PND. Nesse sentido, note-se que antes da intervenção a mo- 
vimentação média em Portonave era entre 5 e 6 mil toneladas por navio, sendo que a partir de 2013 essa média estabilizou-se em torno de $10 \mathrm{mil}$ toneladas - vide Apêndice 2. Caso essa conjectura seja válida, talvez seja possível afirmar que a dragagem gerou impacto na hidrovia do local, apesar de parecer não ter gerado impacto efetivo no porto-alvo do programa.

Em relação ao Rio de Janeiro, nota-se que essa unidade é a quarta maior em movimentação de navios do país, com uma média de 130,7 atracações ao mês no período em tela (ver o Apêndice 1), e, ao mesmo tempo, é um dos portos que apresenta menor movimentação de carga por navio - em torno de 5 mil toneladas. Seguindo as conclusões de TCU (2014), no caso do Rio de Janeiro, a ausência de indicativos de ganhos de eficiência relacionados com o PND pode estar bastante relacionada com a falta de obras complementares em terra, para dar apoio de logística na movimentação de carga, o que limitaria os movimentos portuários de carregamento/descarregamento - e essa mesma explicação valeria para o caso de Suape, o quinto porto mais movimentado do país (SEP 2015).

Já Santos é o porto mais movimentado do país e, por conta disso, possivelmente foi a intervenção mais complexa do PND. Sendo que há pelo menos três explicações para os resultados do controle sintético não sugerirem que o programa tenha causado impacto nesse caso (Torres et al. 2009; TCU 2014; SEP 2015). Primeiro, como o fluxo de navios é intenso, haveria mais deslocamento de sedimentos no fundo dos canais de atracação, e, portanto, a manutenção precisaria ser mais frequente para gerar resultados. Segundo, uma série de empecilhos financeiros, de engenharia e de ambientais atrasaram várias vezes as adequações dos berços de atracação para as novas profundidades. Terceiro, em Santos também houve por uma obra de derrocagem, que se refere à explosão de pedras do leito do canal, então o fato disso ter ocorrido em período diferente da dragagem pode ter refletido nos resultados.

Partindo agora para a análise dos casos em que o controle sintético indica a não rejeição da hipótese de que o PND aumentou a eficiência de carregamentos/descarregamentos, a começar pelo caso de Aratu, nota-se que esta é a principal instalação de movimentação de graneis líquidos e sólidos da Bahia (Carvalho et al. 2015), e que suas obras foram concluídas em fevereiro de 2011, portanto, o número de períodos pré-intervenção observados é $\tau=13$, conforme é ilustrado na Figura 3. Aratu é particularmente importante na movimentação de combustíveis e gases liquefeitos, com 
características similares ao terminal da Dow Química (uma das maiores fabricantes mundiais de produtos químicos e plásticos), o que explica seu maior peso no controle sintético, de 0,50.

\begin{tabular}{|l|cc|}
\hline Preditor & Observado & Sintético \\
\hline Movimentação & 10,5 & 10,5 \\
DWT & 26,9 & 28,2 \\
Calado & 7,7 & 7,9 \\
Longo curso & 70,8 & 60,0 \\
Brasileiros & 18,0 & 18,7 \\
G. de sólidos & 20,0 & 24,1 \\
G. de líquidos & 55,4 & 57,2 \\
Carga Geral & 8,1 & 10,1 \\
Conteineiros & 0,2 & 6,0 \\
& & \\
\hline
\end{tabular}

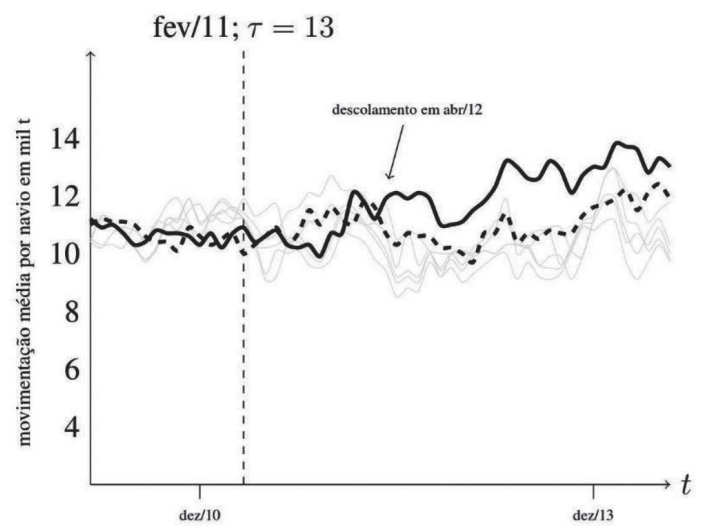

Figura 3 - Resultados estimados para Aratu (BA).

As linhas preta, tracejada e cinzas representam, respectivamente, as trajetórias observada, sintética e placebos para a movimentação média por navio.

O quadro ao lado esquerdo da Figura 3 ilustra as aproximações entre $\bar{Y}_{1 t}$ (observado) e $\sum_{j=2}^{J+1} \widehat{w}_{j}^{*} \bar{Y}_{j t}$ (sintético), e entre $Z_{1}$ (observado) e $\sum_{j=2}^{J+1} \widehat{w}_{j}^{*} Z_{j}$ (sintético), com o objetivo de verificar o ajuste do controle sintético como um todo. Nesse sentido, note que com precisão de uma casa decimal a movimentação de carga por navio está perfeitamente mimetizada - na ordem de 10,5 mil toneladas. Quanto aos outros preditores, usando como referência os trabalhos de Abadie e Gardeazabal (2003) e Abadie et al. (2010, 2011, 2015), que chegam a considerar diferenças de até 20 pontos percentuais em um ou outro preditor como razoáveis, desde que a média observada do indicador de impacto esteja bem aproximada pelo controle sintético, a capacidade de carga e o calado dos navios, assim como os percentuais deles em navegação de longo curso, com bandeira brasileira e por tipo de embarcação estão razoavelmente bem mimetizados.

$\mathrm{Na}$ Figura 3 as linhas preta, tracejada e cinzas representam, respectivamente, as trajetórias observada, sintética e as placebos (cinco nesse caso, já que há cinco doadores) para a movimentação média por navio. Observe que até o ponto $\tau$ (e um pouco depois) as trajetórias se sobrepõem, o que é reflexo do ajuste do controle sintético, mas que em determinado ponto há 
um descolamento entre elas. Este momento é em abril de 2012, conforme indicado, quando em média a movimentação observada passar a ser de 12,3 mil t/navio, e da média do controle sintético é de 11,5 (uma diferença de $0,8 \mathrm{mil} \mathrm{t} /$ navio, ou 7,0\%). Assim, isso sugere que houve um impacto positivo do PND em Aratu.

Nesse caso, a percepção do impacto cerca de um ano depois do fim das obras pode estar relacionada com pelo menos quatro fatores (SEP 2015). Primeiro, durante o processo de verificação e homologação das novas profundidades nos canais de atracação, a Marinha pode requerer adaptações e mudanças de sinalizações, o que pode atrasar o uso efetivo das novas condições nas vias dragadas. Segundo, as novas profundidades permitem uma maior movimentação de carga por navio dentro de determinado mês, uma vez que reduzem a probabilidade de ter de esperar a maré subir para manobrar com segurança, mas, em última instância, para que haja esse aumento é necessário um aumento da atividade econômica que demanda os serviços portuários, e esta pode estar descompassada do momento de término das obras. Terceiro, mesmo que a Marinha homologue as novas profundidades imediatamente ao fim da dragagem e que haja demanda para movimentar mais carga por navio, os ajustes da estrutura em terra podem estar descompassados, o que também geraria atrasos na observação da efetividade dos impactos do programa. Quarto, há um fator de rigidez de contratos, pois há uma certa demora para o estabelecimento de novas linhas de navegação com navios de maior porte, ou mesmo a substituição por um navio maior em uma linha de navegação já existente. É claro, essas observações valem para todos os casos.

\begin{tabular}{|l|cc|}
\hline Preditor & Observado & Sintético \\
\hline & & \\
\hline Movimentação & 8,4 & 8,5 \\
DWT & 28,5 & 29,3 \\
Calado & 8,1 & 8,2 \\
Longo curso & 48,8 & 44,8 \\
Brasileiros & 27,3 & 18,2 \\
G. de sólidos & 13,8 & 14,0 \\
G. de líquidos & 33,0 & 34,0 \\
Carga Geral & 11,2 & 9,5 \\
Conteineiros & 32,1 & 29,7 \\
& & \\
\hline
\end{tabular}

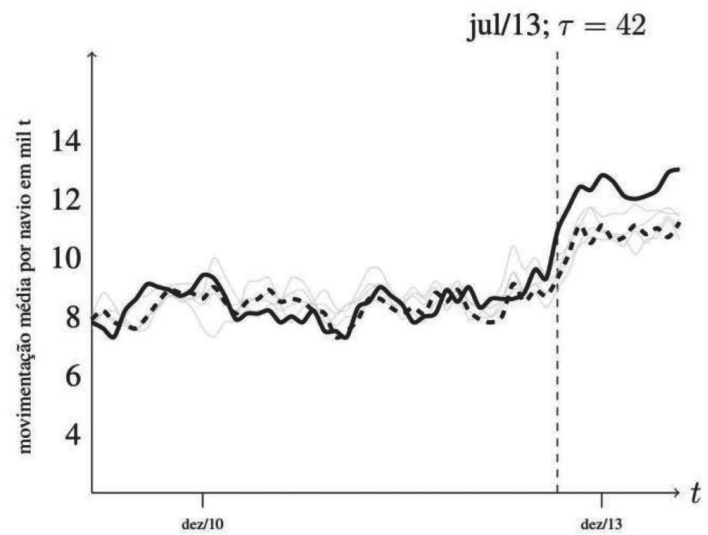

Figura 4 - Resultados estimados para Fortaleza - Porto do Mucuripe (CE). 
Já a Figura 4 apresenta os resultados para Fortaleza, também conhecido como Porto do Mucuripe, sendo que suas obras foram concluídas em julho de 2013, portanto, o número de períodos pré-intervenção observados é $\tau$ $=42$. Nesse caso, o doador de maior peso foi o Belém $(0,78)$. O que chama atenção nesse sentido, além das similaridades numéricas que podem ser observadas no Apêndice 1, é que os portos de Fortaleza e Belém estão inseridos dentro dos seus respectivos contextos urbanos, e ambos recebem cargas bastante heterogêneas. De forma semelhante ao caso anterior, porém mais imediata ao fim das obras, os resultados sugerem que a dragagem pode ter causado um aumentado de $1,1 \mathrm{mil} \mathrm{t} /$ navio na movimentação observada no Porto do Mucuripe em relação ao seu controle sintético - ou $9,8 \%$ - diferença entre 12,3 e 11,2 .

A Figura 5 apresenta os resultados para Rio Grande, o terceiro porto mais movimentado do país, com uma média de 156,3 navios atracados ao mês, e o segundo maior investimento do PND, na ordem de $\mathrm{R} \$ 201,7$ milhões - vide Tabela 1. Chama a atenção o ciclo da movimentação de cargas, com picos no meio do ano, o que decorre das safras agrícolas por lá escoadas. Nesse caso, os resultados sugerem um descolamento da trajetória observada em relação ao sintético nas safras de 2013 e 2014 em cerca de mil t/ navio - ou 10,5\% - diferença entre o observado de 10,5 e o contrafactual estimado em $9,5.7$

\begin{tabular}{|l|cc|}
\hline Preditor & Observado & Sintético \\
\hline Movimentação & 7,4 & 7,4 \\
DWT & 45,3 & 42,9 \\
Calado & 9,6 & 9,4 \\
Longo curso & 68,5 & 68,0 \\
Brasileiros & 8,2 & 6,8 \\
G. de sólidos & 10,4 & 9,4 \\
G. de líquidos & 7,9 & 3,7 \\
Carga Geral & 7,1 & 11,7 \\
Conteineiros & 65,6 & 71,8 \\
& & \\
\hline
\end{tabular}

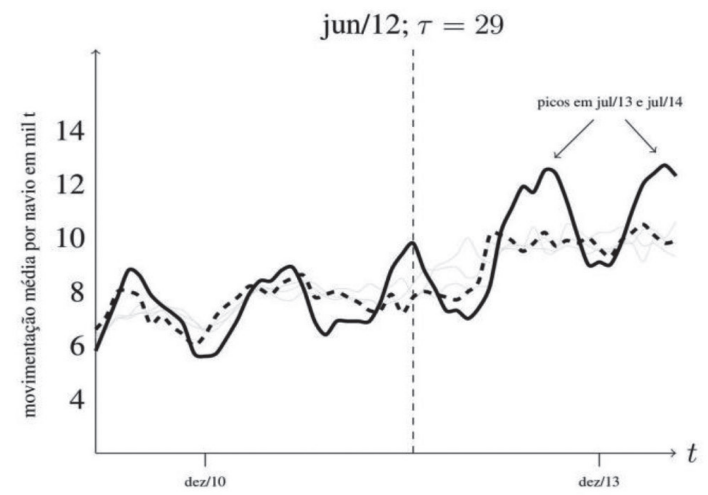

Figura 5 - Resultados estimados para Rio Grande (RS).

\footnotetext{
7 Para uma ilustração da importância das safras na movimentação de Rio Grande, ver, por exemplo, as matérias: "Porto do Rio Grande registra recorde de movimentação", do dia 28/06/2016, no Jornal do Comércio (RS); e, "Porto do Rio Grande movimenta mais de um milhão de toneladas de soja por mês", do dia 30/05/2016, na revista Portos e Navios.
} 
A Figura 6 apresenta os resultados estimados para São Francisco do Sul, que pode ser a instalação que obteve os melhores resultados com as dragagens. Nesse sentido, note que há um claro descolamento de tendência em relação ao controle sintético a partir de abril de 2013, quando a média do indicador de impacto aumenta em cerca de quatro mil t/navio - ou 25,3\% - diferença entre uma média observada de 19,8 e um contrafactual estimado em 15,8. A possível explicação para isso é que, além do governo de Santa Catarina, controlador da instalação, ter promovido várias melhorias de infraestrutura nos últimos anos, a unidade está próxima de Paranaguá - cerca de $70 \mathrm{Km}$ - sendo que este último é o segundo porto mais movimentado do país, e está no limite de sua capacidade operacional (SEP 2015). Assim, São Francisco do Sul pode estar se tornando uma alternativa em relação a Paranaguá, e o aprofundamento dos canais de atracação está permitindo o recebimento de navios de maior calado.

\begin{tabular}{|l|cc|}
\hline Preditor & Observado & Sintético \\
\hline & & \\
Movimentação & 14,1 & 14,0 \\
DWT & 40,7 & 40,0 \\
Calado & 9,0 & 9,0 \\
Longo curso & 71,3 & 76,2 \\
Brasileiros & 15,0 & 14,9 \\
G. de sólidos & 25,7 & 24,0 \\
G. de líquidos & 0,7 & 4,9 \\
Carga Geral & 15,0 & 11,5 \\
Conteineiros & 53,8 & 50,7 \\
& & \\
\hline
\end{tabular}

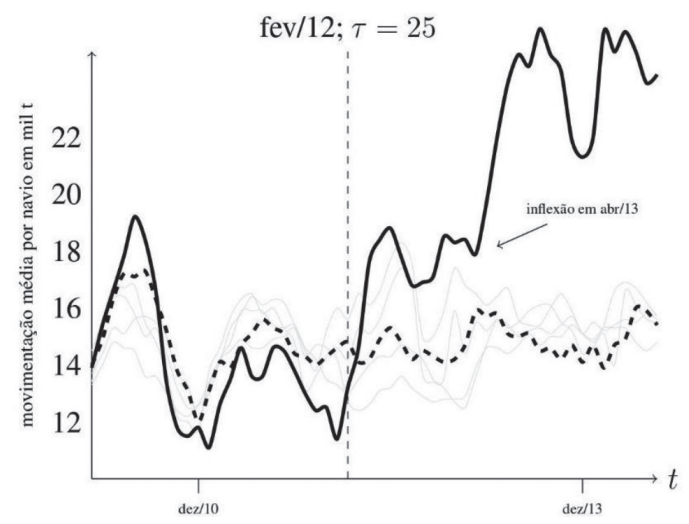

Figura 6 - Resultados estimados para São Francisco do Sul (SC).

Em suma, os resultados do controle sintético indicam que o PND permitiu um aumento da movimentação de carga em Aratu (em cerca de 0,8 mil t/ navio), em Fortaleza $(1,1)$, em Rio Grande $(1,0)$ e em São Francisco do Sul $(4,0)$. Assim, é possível inferir o incremento de receitas portuárias derivado do PND, a fim de compará-los com os valores investidos. Para tal, com base em CODESP (2009), ANTAQ (2015) e SEP (2015), estimou-se que a receita descontada do custo corrente de prestação dos serviços portuários - i.e., a receita operacional líquida - é de em torno de $6,10 \mathrm{R} \$ / \mathrm{t}$ em Aratu, de 6,24 R \$/t em Fortaleza, de 0,26 R \$/t em Rio Grande e de 1,71 R \$/t em São Francisco do Sul - valores de 2015 que dependem do tipo de carga movimentada e do perfil de serviços prestados em cada instalação. 
Tabela 5 - Comparação entre benefícios estimados em receitas líquidas dos portos e investimento do PND. Fonte dos dados: SEP e ANTAQ.

\begin{tabular}{l|cccc}
\hline Indicador & Aratu & Fortaleza & Rio Grande & S. Fr ${ }^{\text {co }}$ do Sul \\
\hline Impacto estimado (mil t/navio) & 0,8 & 1,1 & 1,0 & 4,0 \\
Receita operacional lquida (R\$/t) & 6,10 & 6,24 & 0,26 & 1,71 \\
Movimentação estimada (navios/ano) & 500 & 500 & 2.000 & 750 \\
Impacto anual do PND (R\$ milhões) & 2,4 & 3,4 & 0,5 & 5,1 \\
Investimento do PND (R\$ milhões) & 41,2 & 53,0 & 201,7 & 102,0 \\
Payback estimado (anos) & 17 & 15 & 388 & 20 \\
\hline
\end{tabular}

Elaboração própria.

Considerando então a estimativa de navios atracados ao ano, no período pós PND, em torno de 500 em Aratu e Fortaleza, 2.000 em Rio Grande e 750 em São Francisco do Sul, foi possível estimar que o impacto anual do programa foi de: 2,$4 ; 3,4 ; 0,5$; e, 5,1 milhões de reais em ganhos de receita operacional em cada instalação, respectivamente - como sumarizado na Tabela 5. Comparando então os valores de receita operacional incrementada com os valores investidos pelo PND, é possível inferir que o payback do programa é de menos de duas décadas para os casos de Aratu, Fortaleza e São Francisco do Sul, mas de quase quatro séculos no caso de Rio Grande - o que indica que, neste caso, em termos eminentemente de ganhos de receitas operacionais de prestação de serviços portuários, o impacto notado não foi suficientemente grande para justificar o valor empenhado. Além disso, dado que o valor global do PND foi de R $\$ 1,1$ bilhão, e considerando apenas os ganhos de receita operacional dessas quatro instalações, na casa de $R$ \$ 12,9 milhões ao ano, ceteris paribus, o payback do programa seria de mais de um século. Portanto, isso é um indicativo de que o PND precisa ser aprimorado para galgar resultados mais efetivos.

Por fim, cabe ressaltar que a análise promovida nessa pesquisa debruçou-se sobre um indicador de impacto em específico - a movimentação de carga, ou prancha média - relacionada com o aumento de eficiência, a redução dos custos de transporte e a possibilidade de se receber navios de maiores dimensões. Entretanto, podem existir outros indicadores, até mesmo intangíveis ou de difícil mensuração, sobre os quais o PND pode ter cau- 
sado impactos importantes, mas que não foram dimensionados - e.g., uma eventual aprendizagem das unidades portuárias e empresas nacionais para ligar com grandes obras de desobstrução, remoção e derrocamento das hidrovias nacionais. Portanto, é possível que, muito em consequência dessas experiências, as futuras versões do PND possam galgar melhores resultados e, consequentemente, favorecer as atividades de logística nacional e internacional no Brasil.

\section{Conclusões}

A tendência mundial de se construir navios maiores tem se justificado como forma de reduzir o custo do frete a partir do aumento do volume de carga transportada por viagem. Mas para que os portos possam receber navios maiores, e assim usufruir dessas economias de escala, uma condição necessária é o aprofundamento dos canais de acesso e berços de atracação. Muito embora isso não seja condição suficiente, uma vez que equipamentos portuários e infraestrutura terrestre também precisam ser modernizados para que os custos do frete sejam efetivamente reduzidos.

Nesse novo contexto da logística mundial, desde o início da década de 1990, quando o governo federal deixou de ser responsável pelo planejamento e execução das obras de dragagem, a manutenção da profundidade dos acessos aquaviários brasileiros passou a ser precária. $\mathrm{O}$ que restringiu o acesso de navios maiores, que frequentemente precisavam (ou ainda precisam) esperar a maré subir acima de um nível regular para manobrar com segurança. Consequentemente, isso contribuiu para o aumento dos custos globais de frete por conta dos custos de demurrage e seguros mais caros. Que em última instância vem gerando um novo obstáculo para a logística do Brasil, em especial para o comércio exterior, já que mais de $80 \%$ das transações com o resto do mundo são feitas por esse modal - detalhes em IPEA (2010).

Em 2007, quando ocorreu a concepção do PND, percebeu-se a necessidade do governo federal retomar a responsabilidade das obras de dragagem, pelo menos em parte, dos portos nacionais, sob o risco dos resultados da balança comercial começarem a ser comprometidos (Campos Neto et al. 
2009). Assim, entre 2009 e 2013, o programa promoveu intervenções em 15 portos públicos, com um investimento total da ordem de $\mathrm{R} \$ 1,1$ bilhão.

Dado esse cenário, a pesquisa aqui relatada encontrou indicativos que o PND melhorou a eficiência da movimentação de carga em quatro dos portos tratados: Aratu (aumento de 7,0\% em relação ao contrafactual estimado pelo controle sintético); Fortaleza (9,8\%); Rio Grande (10,5\%); e, São Francisco do Sul (25,3\%). Todavia, conforme o exercício de comparação de custo/benefício apresentado, estes resultados não seriam suficientemente grandes para cobrir o investimento de R \$ 1,1 bilhão no PND - muito embora perceba-se que o programa não pode ser abandonado porque é estratégico para se reduzir os custos de frete e logística e melhorar a inserção do Brasil no comércio internacional (SEP 2015).

É possível que a não identificação de impactos nas demais instalações seja um reflexo das dificuldades historicamente enfrentadas pelos portos nacionais para realização de obras de infraestrutura em geral, como é largamente discutido por Goularti Filho (2007). Particularmente em relação as dragagens, conforme identificado na análise histórica feita por Fadda (2012), nos períodos em que as próprias autoridades portuárias ficaram encarregadas das obras ocorreram inúmeras dificuldades em realizá-las, ocasionando gargalos e perda de capacidade de seus acessos aquaviários. Sendo que possivelmente isso seja uma consequência do fato de que esse tipo de obra, em sua maior parte, apresenta baixos retornos econômicos para as autoridades portuárias. Todavia, no contexto nacional, as dragagens são de cunho estratégico para o comércio exterior. Portanto, essas obras demandam uma melhora de planejamento, monitoramento e avaliação como é enfatizado em TCU (2014), onde se encontra uma avaliação alternativa, ou mesmo complementar, do estudo aqui relatado.

Assim, considerando as externalidades econômicas positivas geradas por estas obras para o país, ${ }^{8}$ e não apenas as receitas dos serviços portuários que são apropriadas apenas pelas autoridades controladoras, existe ainda a possibilidade de ampliar os retornos desses investimentos ao envolver outras entidades que se beneficiam das dragagens, diluindo assim, o ônus financeiro do investimento. Especificamente, é possível que modelos de concessão que permitam uma composição de concessionários mais ampla

8 Externalidades positivas na perspectiva econômica, embora existam externalidades negativas ambientais que não devem ser menosprezadas - detalhes em Torres et al. (2009) e Castro e Almeida (2012). 
possam permitir a continuidade dos investimentos sem onerar o poder concedente - ou seja, talvez seja possível que uma nova configuração institucional possa levar a uma situação Pareto Superior. ${ }^{9} \mathrm{O}$ que certamente é um tema relevante para pesquisas futuras.

\section{Referências}

Abadie,A. and J. Gardeazabal. 2003. "The Economic Costs of Conflict: ACase Study of the Basque Country". The American Economic Review 93(1): 113-132, jstor.org/ stable/3132164.

Abadie, A., A. Diamond, and J. Hainmueller. 2010. "Synthetic Control Methods for Comparative Case Studies: Estimating the Effect of California's Tobacco Control Program". Journal of the American Statistical Association 105(490): 493-505, jstor.org/ stable/29747059.

Abadie, A., A. Diamond, and J. Hainmueller. 2011. "Synth: An R Package for Synthetic Control Methods in Comparative Case Studies”. Journal of Statistical Software 42(13): 1-17, web.stanford.edu/ jhain/Paper/ JSS2011.pdf.

Abadie,A., A. Diamond, and J. Hainmueller. 2015. "Comparative Politics and the Synthetic Control Method". American Journal of Political Science 59(2): 495-510, onlinelibrary.wiley.com/doi/10.1111/ajps.12116/epdf.

Akabane, G., and M. Gonçalves. 2008. “A importância do modelo de autoridade portuária como opção no planejamento logístico". Revista Brasileira de Estratégia 1(1): 19-28, http://www2.pucpr.br/reol/pb/index.php/ rebrae?dd1 $=2076 \&$ dd99 $=$ view $\& d d 98=$ pb.

Albertijn, S., W. Bessler, and W. Drobetz. 2011. 'Financing Shipping Companies and Shipping Operations: A Risk-Management Perspective". Journal of Applied Corporate Finance 23(4): 70-82, onlinelibrary.wiley. com/doi/10.1111/j.1745-6622. 2011.00353.x/pdf.

ANTAQ, 2015. Relatório de desempenho portuário de 2015. Agência Nacional de Transporte Aquaviários, http:// www.antaq.gov.br/portal/DesempenhoPortuario.

Athey, Susan and Guido Imbens. 2016. The State of AppliedEconometrics-Causality and Policy Evaluation. Mimeo, Cornel University, https://arxiv.org/abs/1607.00699.

Bernhofen, D., Z. El-Sahli, and R. Kneller. 2016. "Estimating the effects of the container revolution on world trade". Journal of International Economics 98:36-50, http://www.sciencedirect.com/science/article/ pii/S0022199615001403.

Britto, P. et al. 2015. "Promoção da concorrência no setor portuário: uma análise a partir dos modelos mundiais e aplicação ao caso brasileiro". Revista de Administração Pública 49(1): 47-71, scielo.br/pdf/ rap/v49n1/ 0034-7612-rap-49-01-00047.pdf.

Campos Neto, C. et al. 2009. "Gargalos e demandas da infraestrutura portuária e os investimentos do PAC: mapeamentos IPEA de obras portuárias". Texto para Discussão, IPEA, 1423, ipea.gov.br/portal/images/ stories/PDFs/TDs/td_1423.pdf.

Carvalho, A. et al. 2015. "Caracterização do Fluxo de Cargas e Indicadores de Concorrência entre os Portos Brasileiros". Texto para Discussão, IPEA 2091, ipea.gov.br/portal/images/stories/PDFs/ TDs/td_2091.pdf.

Castro, S. and J. Almeida. 2012. "Dragagem e conflitos ambientais em portos clássicos e modernos: uma revisão". Sociedade \& Natureza 24(3): 519-534, www.scielo.br/ pdf/sn/v24n3/v24n3a11.pdf.

9 Tais como condomínios portuários, consórcios de empresas ou modelos tripartite - detalhes em Akabane e Gonçalves (2008). 
CODESP. 2009. "Plano de Desenvolvimento e Expansão do Porto de Santos". Companhia Docas do Estado de São Paulo, relatório do empréstimo ATN/OC-10694-BR junto ao Banco Interamericano de Desenvolvimento, BID, portosdobrasil.gov.br/assuntos-1/ relacoes-internacionais/arquivos/relatorio-final-plano-diretor-bid.pdf.

Cortez, L. C. S. et al. 2013. “Análise de eficiência na gestão de portos públicos brasileiros em relação ao papel das autoridades portuárias". Journal of Transport Literature 7(2): 78-96, scielo.br/pdf/jt1/ v7n2/v7n2a05.pdf.

Cullinane, K. and Khanna, M. 1999. "Economies of Scale in Large Container Ships". Journal of Transport Economics and Policy 33(2): 185-207, jstor.org/stable/ 20053805.

Cullinane, K. and Khanna, M. 2000. "Economies of scale in large containerships: optimal size and geographical implications". Journal of Transport Geography 8:181-195, sciencedirect.com/science/article/pii/ S0966692300000107.

Fadda, E. A. 2012. "Instrumentos legais aplicados à dragagem no Brasil. Revista Direito Aduaneiro,Marítimo e Portuários". Revista DireitoAduaneiro, Marítimoe Portuários 06, Grupo IOB, antaq.gov.br/portal/Pdf/ PublicacoesTecnicas/ArtigoElianeFadda. pdf.

Goularti Filho, A. 2007. 'Melhoramentos, reaparelhamentos e modernização dos portos brasileiros: a longa e constante espera". Economia e Sociedade 16(3): 455-489, scielo.br/pdf/ecos/v16n3/07.

Gertler, Paul J. et al. 2016. Impact evaluation in practice, World Bank Publications, https://openknowledge. worldbank.org/handle/10986/25030.

Grammenos, Costas. 2013. The handbook of maritime economics and business, Taylor \& Francis, ISBN 9781135134068.

Hornok,C.; Koren, M. 2015. "Per-shipment costs and the lumpiness of international trade". Review of Economics and Statistics 9: 525-530, http://www.mitpressjournals. org/doi/abs/10.1162/REST_a_00468.

Hummels, D. 2007. "Transportation Costs and International Trade in the Second Era of Globalization". The Journal of Economic Perspectives 21(3): 131-154, jstor.org/ stable/30033762.

Imai, A.; E. Nishimura; S. Papadimitriou, and M. Liu. 2006. "The economic viability of container mega-ships". Transportation Research 42: 21-41, sciencedirect.com/ science/article/pii/S1366554504000584.

IPEA2010.'InfraestruturaEconômica no Brasil: diagnósticoseperspectivaspara2025”.'Instituto de Pesquisa Econômica Aplicada, livro 6(1), http://repositorio.ipea. gov.br/bitstream/11058/3210/1/Livro6_InfraestruturaSocial_vol1.pdf.

Khandker, S.; G. Koolwal, and H. Samad. 2010. Handbook on Impact Evaluation: Quantitative Methods and Practices, The World Bank, Washington DC, openknowledge. worldbank.org/handle/10986/2693.

Levinson, Marc. 2013. The box: How the Shipping Container Made the World Smaller and the World Economy Bigger. EGEA spa, ISBN 978140082858.

Marchetti, D. and T. Ferreira. 2014. "Situação atual e perspectivas da infraestrutura de transportes e da logśtica no Brasil”. Perspectivas Setoriais, BNDES 235, bndes.gov.br/SiteBNDES/export/sites/default/bndes_pt/Galerias/ Arquivos/conhecimento/livro60anos_perspectivas_setoriais/Setorial60anos_VOL2Logistica.pdf

Menegazzo,L.R. andA.L. Fachinello.2014. “Análise de nível de eficiência dos portos brasileiros”. Revista de Economia 40(3): 173-197, revistas.ufpr.br/economia/article/view/42419.

Notteboom, T. 2004. "Container Shipping And Ports: An Overview". Review of Network Economics 3(2): 86-106, vliz.be/imisdocs/publications/278392.pdf.

Pascali, Luigi. 2017. "The wind of change: Maritime technology, trade and economic development", American Economic Review (forthcoming), https://www.aeaweb.org/ journals/aer/forthcoming.

Rodrigues, Paulo Roberto A. 2008. Introdução aos sistemas de transporte no Brasil e à logística internacional. Edições Aduaneiras, ISBN 9788571294905.

Rubin, D. 2005. Causal Inference Using Potential Outcomes: Design, Modeling, Decisions. Journal of the American Statistical Association 100(469): 322-331, jstor.org/ stable/27590541. 
Schwab, K., and Sala-I-MartÍn, X. 2014. “The Global Competitiveness Report 2014-2015, Full Data Edition”, World Economic Forum, http://www3.weforum.org/docs/WEF_GlobalCompetitivenessReport_2014-15.pdf.

SEP. 2015. Plano Nacional de Logística Portuária, Secretaria dos Portos da Presidência da República, SEP, http://www.portosdobrasil.gov.br/assuntos-1/pnpl/ plano-nacional-de-logistica-portuaria.

Talley, W. 2000. “Ocean Container Shipping: Impacts of a Technological Improvement”. Journal of Economic Issues 34(4): 933-948, tandfonline.com/doi/pdf/10.1080/ 00213624.2000.11506322.

TCU. 2014. Relatório Técnico do Processo TC 009.504/2013-3. Tribunal de Contas da União (TCU), http://www.tcu.gov.br/Consultas/Juris/Docs/judoc/Acord/20140402/AC_0735_09_14_P.doc.

Torres, R. et al. 2009. "Effects of dredging operations on sediment quality: contaminant mobilization in dredged sediments from the Port of Santos, SP, Brazil". Journal of Soils and Sediments 9(5): 420-432, link.springer.com/article/10.1007/ s11368-009-0121-x.

Tran, N., and Haasis, H. 2015. "An empirical study of fleet expansion and growth of shipsize in container linershipping". International Journal of Production Economics 159: 241-253, sciencedirect.com/science/article/pii/ S0925527314002941.

UNCTAD. 2015. Review of Maritime Transport. United Nations Conference on Trade and Development, Genebra, Suíça, unctad.org/en/PublicationsLibrary/rmt2015_en.pdf. 


\section{Apêndice 1}

Médias entre fev/10-ago/14 e desvios padrão (em parênteses), por instalação portuária, do número de navios de carga atracados, movimentação, DTW e calado dos navios, e percentuais deles em navegação de longo curso, com bandeira brasileira e especialidade de carregamento.

\begin{tabular}{|c|c|c|c|c|c|c|c|c|c|c|}
\hline Instalações & 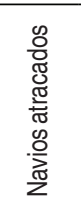 & 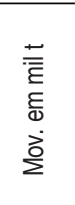 & 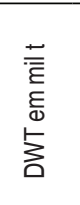 & $\begin{array}{l}E \\
E \\
E \\
\mathbb{0} \\
\frac{0}{0} \\
\frac{\mathbb{\sigma}}{\mathbb{J}} \\
\mathcal{J}\end{array}$ & 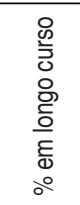 & 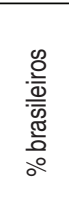 & 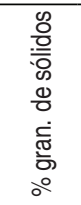 & 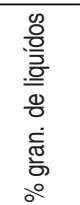 & 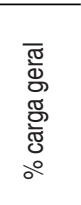 & 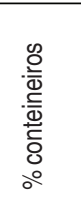 \\
\hline Tratadas & & & & & & & & & & \\
\hline Aratu (BA) & $\begin{array}{l}41,4 \\
(5,1)\end{array}$ & $\begin{array}{c}11,5 \\
(1,2)\end{array}$ & $\begin{array}{l}27,6 \\
(1,5)\end{array}$ & $\begin{array}{c}7,7 \\
(0,1)\end{array}$ & $\begin{array}{l}68,9 \\
(4,5)\end{array}$ & $\begin{array}{l}19,4 \\
(4,3)\end{array}$ & $\begin{array}{c}19,0 \\
(4,3)\end{array}$ & $\begin{array}{l}57,0 \\
(4,2)\end{array}$ & $\begin{array}{c}\mathbf{5 , 4} \\
(3,1)\end{array}$ & $\begin{array}{c}0,1 \\
(0,3)\end{array}$ \\
\hline Fortaleza (CE) & $\begin{array}{l}41,3 \\
(5,2)\end{array}$ & $\begin{array}{r}9,3 \\
(1,7)\end{array}$ & $\begin{array}{l}28,7 \\
(1,0)\end{array}$ & $\begin{array}{c}8,1 \\
(0,1)\end{array}$ & $\begin{array}{l}47,3 \\
(4,7)\end{array}$ & $\begin{array}{l}\mathbf{2 5 , 5} \\
(5,9)\end{array}$ & $\begin{array}{l}13,5 \\
(2,8)\end{array}$ & $\begin{array}{l}32,3 \\
(2,9)\end{array}$ & $\begin{array}{l}11,1 \\
(2,9)\end{array}$ & $\begin{array}{l}32,7 \\
(3,2)\end{array}$ \\
\hline Itaguaí (RJ) & $\begin{array}{l}82,9 \\
(9,0)\end{array}$ & $\begin{array}{l}59,0 \\
(8,7)\end{array}$ & $\begin{array}{l}89,3 \\
(7,4)\end{array}$ & $\begin{array}{l}11,3 \\
(0,3)\end{array}$ & $\begin{array}{c}70,7 \\
(6,2)\end{array}$ & $\begin{array}{l}17,1 \\
(2,8)\end{array}$ & $\begin{array}{l}38,0 \\
(4,4)\end{array}$ & $\begin{array}{c}0,0 \\
(0,0)\end{array}$ & $\begin{array}{c}3,1 \\
(1,1)\end{array}$ & $\begin{array}{l}56,9 \\
(4,6)\end{array}$ \\
\hline Itajaí (SC) & $\begin{array}{r}45,5 \\
(11,7)\end{array}$ & $\begin{array}{r}7,5 \\
(1,1)\end{array}$ & $\begin{array}{l}50,5 \\
(8,2)\end{array}$ & $\begin{array}{l}10,1 \\
(0,7)\end{array}$ & $\begin{array}{r}61,6 \\
(11,5)\end{array}$ & $\begin{array}{c}10,9 \\
(5,4)\end{array}$ & $\begin{array}{r}0,0 \\
(0,2)\end{array}$ & $\begin{array}{c}0,0 \\
(0,0)\end{array}$ & $\begin{array}{c}0,5 \\
(0,7)\end{array}$ & $\begin{array}{l}99,1 \\
(1,0)\end{array}$ \\
\hline Natal (RN) & $\begin{array}{c}6,1 \\
(1,9)\end{array}$ & $\begin{array}{c}5,0 \\
(1,3)\end{array}$ & $\begin{array}{l}20,6 \\
(1,7)\end{array}$ & $\begin{array}{c}7,9 \\
(0,3)\end{array}$ & $\begin{array}{c}80,3 \\
(10,2)\end{array}$ & $\begin{array}{c}2,7 \\
(3,6)\end{array}$ & $\begin{array}{l}15,5 \\
(5,8)\end{array}$ & $\begin{array}{c}0,0 \\
(0,0)\end{array}$ & $\begin{array}{l}10,6 \\
(9,0)\end{array}$ & $\begin{array}{l}69,4 \\
(11,5)\end{array}$ \\
\hline Rio de Janeiro (RJ) & $\begin{array}{l}130,7 \\
(18,9)\end{array}$ & $\begin{array}{r}5,0 \\
(0,8)\end{array}$ & $\begin{array}{l}43,7 \\
(3,4)\end{array}$ & $\begin{array}{r}9,6 \\
(0,4)\end{array}$ & $\begin{array}{l}69,0 \\
(3,6)\end{array}$ & $\begin{array}{r}2,8 \\
(1,8)\end{array}$ & $\begin{array}{r}4,9 \\
(1,5)\end{array}$ & $\begin{array}{c}3,8 \\
(1,3)\end{array}$ & $\begin{array}{l}12,8 \\
(3,0)\end{array}$ & $\begin{array}{l}69,3 \\
(6,6)\end{array}$ \\
\hline Rio Grande (RS) & $\begin{array}{l}156,3 \\
(15,7)\end{array}$ & $\begin{array}{r}8,6 \\
(2,0)\end{array}$ & $\begin{array}{l}49,5 \\
(5,1)\end{array}$ & $\begin{array}{r}9,9 \\
(0,4)\end{array}$ & $\begin{array}{l}67,6 \\
(1,7)\end{array}$ & $\begin{array}{r}8,0 \\
(1,3)\end{array}$ & $\begin{array}{l}13,2 \\
(4,7)\end{array}$ & $\begin{array}{r}9,3 \\
(1,8)\end{array}$ & $\begin{array}{c}5,9 \\
(1,8)\end{array}$ & $\begin{array}{l}63,7 \\
(3,9)\end{array}$ \\
\hline Salvador (BA) & $\begin{array}{l}73,2 \\
(7,3)\end{array}$ & $\begin{array}{c}4,1 \\
(0,3)\end{array}$ & $\begin{array}{l}43,5 \\
(5,1)\end{array}$ & $\begin{array}{c}9,6 \\
(0,5)\end{array}$ & $\begin{array}{l}58,6 \\
(2,1)\end{array}$ & $\begin{array}{l}21,6 \\
(5,3)\end{array}$ & $\begin{array}{r}3,3 \\
(1,0)\end{array}$ & $\begin{array}{c}0,3 \\
(0,4)\end{array}$ & $\begin{array}{c}8,3 \\
(2,2)\end{array}$ & $\begin{array}{l}82,9 \\
(3,6)\end{array}$ \\
\hline Santos (SP) & $\begin{array}{l}422,2 \\
(37,4)\end{array}$ & $\begin{array}{c}18,0 \\
(1,6)\end{array}$ & $\begin{array}{l}49,0 \\
(5,3)\end{array}$ & $\begin{array}{c}9,8 \\
(0,4)\end{array}$ & $\begin{array}{l}72,2 \\
(5,9)\end{array}$ & $\begin{array}{c}6,3 \\
(0,8)\end{array}$ & $\begin{array}{l}19,6 \\
(2,7)\end{array}$ & $\begin{array}{c}13,3 \\
(1,4)\end{array}$ & $\begin{array}{l}8,3 \\
(1,3)\end{array}$ & $\begin{array}{c}51,9 \\
(3,3)\end{array}$ \\
\hline São $\mathrm{Fr}^{\mathrm{CO}}$ do Sul (SC) & $\begin{array}{l}\mathbf{5 2 , 6} \\
(8,5)\end{array}$ & $\begin{array}{l}17,9 \\
(4,9)\end{array}$ & $\begin{array}{l}41,9 \\
(2,6)\end{array}$ & $\begin{array}{c}9,1 \\
(0,2)\end{array}$ & $\begin{array}{l}70,3 \\
(3,5)\end{array}$ & $\begin{array}{c}17,5 \\
(4,6)\end{array}$ & $\begin{array}{c}33,4 \\
(10,1)\end{array}$ & $\begin{array}{c}0,5 \\
(0,6)\end{array}$ & $\begin{array}{l}15,6 \\
(3,8)\end{array}$ & $\begin{array}{c}44,6 \\
(12,3)\end{array}$ \\
\hline Suape (PE) & $\begin{array}{c}119,8 \\
(8,3)\end{array}$ & $\begin{array}{c}7,9 \\
(1,2)\end{array}$ & $\begin{array}{l}43,9 \\
(1,7)\end{array}$ & $\begin{array}{c}9,5 \\
(0,2)\end{array}$ & $\begin{array}{l}49,1 \\
(2,2)\end{array}$ & $\begin{array}{l}25,4 \\
(3,4)\end{array}$ & $\begin{array}{c}3,2 \\
(0,9)\end{array}$ & $\begin{array}{c}19,0 \\
(3,5)\end{array}$ & $\begin{array}{c}5,0 \\
(1,0)\end{array}$ & $\begin{array}{l}61,4 \\
(3,5)\end{array}$ \\
\hline \multicolumn{11}{|l|}{ Públicas (não tratadas) } \\
\hline Belém (PA) & $\begin{array}{l}25,6 \\
(3,9)\end{array}$ & $\begin{array}{r}8,5 \\
(0,9)\end{array}$ & $\begin{array}{l}\mathbf{2 8 , 3} \\
(2,1)\end{array}$ & $\begin{array}{c}8,1 \\
(0,2)\end{array}$ & $\begin{array}{c}36,5 \\
(5,4)\end{array}$ & $\begin{array}{l}11,9 \\
(3,7)\end{array}$ & $\begin{array}{l}10,0 \\
(2,8)\end{array}$ & $\begin{array}{l}43,2 \\
(4,6)\end{array}$ & $\begin{array}{c}8,1 \\
(3,7)\end{array}$ & $\begin{array}{l}23,4 \\
(4,0)\end{array}$ \\
\hline Imbituba (SC) & $\begin{array}{l}20,4 \\
(4,3)\end{array}$ & $\begin{array}{r}9,7 \\
(1,6)\end{array}$ & $\begin{array}{l}36,6 \\
(6,0)\end{array}$ & $\begin{array}{r}8,8 \\
(0,5)\end{array}$ & $\begin{array}{l}68,2 \\
(3,8)\end{array}$ & $\begin{array}{l}10,9 \\
(8,2)\end{array}$ & $\begin{array}{l}23,3 \\
(6,8)\end{array}$ & $\begin{array}{r}9,3 \\
(3,2)\end{array}$ & $\begin{array}{l}14,6 \\
(5,7)\end{array}$ & $\begin{array}{l}47,4 \\
(9,3)\end{array}$ \\
\hline Itaqui (MA) & $\begin{array}{l}\mathbf{5 2 , 5} \\
(6,8)\end{array}$ & $\begin{array}{l}23,3 \\
(2,0)\end{array}$ & $\begin{array}{l}42,0 \\
(2,1)\end{array}$ & $\begin{array}{c}8,8 \\
(0,2)\end{array}$ & $\begin{array}{c}63,0 \\
(5,6)\end{array}$ & $\begin{array}{r}9,5 \\
(3,7)\end{array}$ & $\begin{array}{l}29,0 \\
(4,5)\end{array}$ & $\begin{array}{l}45,6 \\
(4,5)\end{array}$ & $\begin{array}{l}15,2 \\
(3,4)\end{array}$ & $\begin{array}{c}3,0 \\
(2,5)\end{array}$ \\
\hline eió (AL) & 21,1 & 11,1 & 27,8 & 7,7 & 46,2 & 19,5 & 34,4 & 37,6 & 7,8 & 1,7 \\
\hline Paranåuá(PR) & $\begin{array}{r}(7,1) \\
193,6\end{array}$ & $\begin{array}{l}(3,4) \\
16,5\end{array}$ & $\begin{array}{l}(5,9) \\
50,2\end{array}$ & $\begin{array}{c}(0,7) \\
9,9\end{array}$ & $\begin{array}{c}(17,2) \\
74,3\end{array}$ & $\begin{array}{r}(7,7) \\
5,1\end{array}$ & $\begin{array}{c}(10,9) \\
32,4\end{array}$ & $\begin{array}{c}(11,2) \\
7,1\end{array}$ & $\begin{array}{c}(5,7) \\
3,5\end{array}$ & $\begin{array}{l}(4,2) \\
48,0\end{array}$ \\
\hline Paranaguá(PR) & $\begin{array}{c}(30,9) \\
6,4\end{array}$ & $\begin{array}{c}(1,7) \\
7,9\end{array}$ & $\begin{array}{l}(7,2) \\
36,0\end{array}$ & $\begin{array}{c}(0,5) \\
8,5\end{array}$ & $\begin{array}{l}(5,6) \\
78,7\end{array}$ & $\begin{array}{c}(1,7) \\
5,6\end{array}$ & $\begin{array}{c}(3,3) \\
82,4\end{array}$ & $\begin{array}{c}(1,1) \\
0,5\end{array}$ & $\begin{array}{l}(1,1) \\
16,3\end{array}$ & $\begin{array}{c}(3,9) \\
0,0\end{array}$ \\
\hline Porto Alegre (RS) & $(3,1)$ & $(1,2)$ & $(5,8)$ & $(0,4)$ & $(14,2)$ & $(8,9)$ & $(14,0)$ & $(1,6)$ & $(13,1)$ & $(0,0)$ \\
\hline São Sebastião (SP) & $\begin{array}{r}\mathbf{6 , 3} \\
(2,2) \\
\mathbf{5 2 , 1}\end{array}$ & $\begin{array}{r}9,4 \\
(2,3) \\
24,9\end{array}$ & $\begin{array}{c}29,8 \\
(4,8) \\
33,4\end{array}$ & $\begin{array}{c}8,2 \\
(0,3) \\
8,1\end{array}$ & $\begin{array}{l}97,7 \\
(4,8) \\
78,3\end{array}$ & $\begin{array}{c}0,7 \\
(2,5) \\
5,4\end{array}$ & $\begin{array}{c}20,5 \\
(9,1) \\
38,9\end{array}$ & $\begin{array}{r}0,0 \\
(0,0) \\
10,6\end{array}$ & $\begin{array}{c}64,7 \\
(10,3) \\
12,5\end{array}$ & $\begin{array}{c}0,0 \\
(0,0) \\
20,4\end{array}$ \\
\hline Vila do Conde (PA) & $(4,4)$ & $(2,6)$ & $(1,7)$ & $(0,2)$ & $(4,4)$ & $(2,4)$ & $(4,7)$ & $(1,2)$ & $(2,4)$ & $(4,2)$ \\
\hline
\end{tabular}


Apêndice 1 (Continuação)

\begin{tabular}{|c|c|c|c|c|c|c|c|c|c|c|}
\hline Instalações & 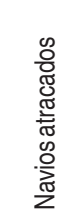 & 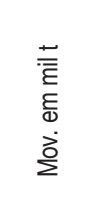 & 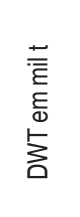 & 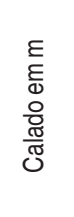 & 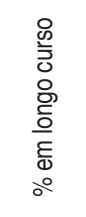 & 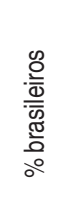 & 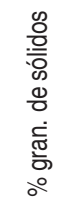 & 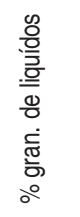 & 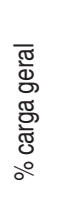 & 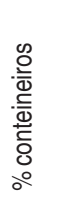 \\
\hline \multicolumn{11}{|l|}{ Privadas } \\
\hline Alumar (MA) & $\begin{array}{l}18,6 \\
(2,6)\end{array}$ & $\begin{array}{l}53,3 \\
(6,6)\end{array}$ & $\begin{array}{l}48,7 \\
(4,6)\end{array}$ & $\begin{array}{c}9,0 \\
(0,2)\end{array}$ & $\begin{array}{l}49,3 \\
(4,5)\end{array}$ & $\begin{array}{l}17,8 \\
(4,8)\end{array}$ & $\begin{array}{l}75,2 \\
(3,6)\end{array}$ & $\begin{array}{l}13,0 \\
(1,6)\end{array}$ & $\begin{array}{l}11,8 \\
(3,4)\end{array}$ & $\begin{array}{c}0,0 \\
(0,0)\end{array}$ \\
\hline Bianchini (RS) & $\begin{array}{l}12,2 \\
(4,1)\end{array}$ & $\begin{array}{c}32,9 \\
(10,2)\end{array}$ & $\begin{array}{l}59,0 \\
(5,4)\end{array}$ & $\begin{array}{c}9,6 \\
(0,2)\end{array}$ & $\begin{array}{l}98,0 \\
(3,1)\end{array}$ & $\begin{array}{c}1,2 \\
(2,1)\end{array}$ & $\begin{array}{l}69,4 \\
(11,6)\end{array}$ & $\begin{array}{c}7,9 \\
(3,9)\end{array}$ & $\begin{array}{c}1,7 \\
(2,7)\end{array}$ & $\begin{array}{c}0,0 \\
(0,0)\end{array}$ \\
\hline Cattalini (PR) & $\begin{array}{l}12,6 \\
(3,1)\end{array}$ & $\begin{array}{l}10,2 \\
(1,3)\end{array}$ & $\begin{array}{l}31,6 \\
(3,1)\end{array}$ & $\begin{array}{c}8,3 \\
(0,3)\end{array}$ & $\begin{array}{l}85,1 \\
(5,4)\end{array}$ & $\begin{array}{c}4,9 \\
(2,5)\end{array}$ & $\begin{array}{c}\mathbf{0 , 2} \\
(0,9)\end{array}$ & $\begin{array}{l}99,6 \\
(1,0)\end{array}$ & $\begin{array}{c}0,0 \\
(0,0)\end{array}$ & $\begin{array}{c}0,0 \\
(0,0)\end{array}$ \\
\hline Chibatão (AM) & $\begin{array}{l}19,0 \\
(7,4)\end{array}$ & $\begin{array}{l}11,3 \\
(1,6)\end{array}$ & $\begin{array}{l}33,3 \\
(3,1)\end{array}$ & $\begin{array}{c}9,2 \\
(0,3)\end{array}$ & $\begin{array}{l}54,4 \\
(5,8)\end{array}$ & $\begin{array}{c}66,1 \\
(11,9)\end{array}$ & $\begin{array}{c}0,0 \\
(0,0)\end{array}$ & $\begin{array}{c}0,0 \\
(0,0)\end{array}$ & $\begin{array}{c}1,6 \\
(2,1)\end{array}$ & $\begin{array}{l}96,2 \\
(6,8)\end{array}$ \\
\hline Cotegipe (BA) & $\begin{array}{c}6,3 \\
(3,0)\end{array}$ & $\begin{array}{l}34,9 \\
(7,4)\end{array}$ & $\begin{array}{l}47,7 \\
(8,0)\end{array}$ & $\begin{array}{c}9,0 \\
(0,3)\end{array}$ & $\begin{array}{l}96,9 \\
(5,0)\end{array}$ & $\begin{array}{c}2,3 \\
(4,3)\end{array}$ & $\begin{array}{l}87,7 \\
(8,8)\end{array}$ & $\begin{array}{c}0,0 \\
(0,0)\end{array}$ & $\begin{array}{l}10,8 \\
(8,1)\end{array}$ & $\begin{array}{c}0,0 \\
(0,0)\end{array}$ \\
\hline Dow Aratu (BA) & $\begin{array}{c}5,0 \\
(1,3)\end{array}$ & $\begin{array}{l}11,6 \\
(1,3)\end{array}$ & $\begin{array}{l}23,8 \\
(3,5)\end{array}$ & $\begin{array}{c}7,6 \\
(0,3)\end{array}$ & $\begin{array}{l}50,4 \\
(7,2)\end{array}$ & $\begin{array}{l}10,7 \\
(8,3)\end{array}$ & $\begin{array}{c}2,6 \\
(4,7)\end{array}$ & $\begin{array}{l}97,4 \\
(4,7)\end{array}$ & $\begin{array}{c}0,0 \\
(0,0)\end{array}$ & $\begin{array}{c}0,0 \\
(0,0)\end{array}$ \\
\hline Dow Guarujá(SP) & $\begin{array}{c}5,6 \\
(1,6)\end{array}$ & $\begin{array}{l}10,4 \\
(1,7)\end{array}$ & $\begin{array}{l}25,0 \\
(4,6)\end{array}$ & $\begin{array}{c}7,7 \\
(0,3)\end{array}$ & $\begin{array}{l}38,5 \\
(9,0)\end{array}$ & $\begin{array}{l}13,9 \\
(9,7)\end{array}$ & $\begin{array}{c}3,8 \\
(6,6)\end{array}$ & $\begin{array}{l}95,9 \\
(6,7)\end{array}$ & $\begin{array}{l}0,0 \\
(0,0)\end{array}$ & $\begin{array}{c}0,0 \\
(0,0)\end{array}$ \\
\hline Murucupi (PA) & $\begin{array}{c}6,2 \\
(1,6)\end{array}$ & $\begin{array}{l}20,4 \\
(1,3)\end{array}$ & $\begin{array}{l}26,4 \\
(1,5)\end{array}$ & $\begin{array}{c}7,5 \\
(0,2)\end{array}$ & $\begin{array}{l}97,1 \\
(2,7)\end{array}$ & $\begin{array}{c}1,2 \\
(2,6)\end{array}$ & $\begin{array}{l}38,9 \\
(8,6)\end{array}$ & $\begin{array}{c}1,5 \\
(2,6)\end{array}$ & $\begin{array}{l}59,6 \\
(8,8)\end{array}$ & $\begin{array}{c}0,0 \\
(0,0)\end{array}$ \\
\hline Pecém (CE) & $\begin{array}{l}52,9 \\
(7,4)\end{array}$ & $\begin{array}{c}7,9 \\
(3,0)\end{array}$ & $\begin{array}{l}43,3 \\
(4,4)\end{array}$ & $\begin{array}{c}9,5 \\
(0,4)\end{array}$ & $\begin{array}{l}62,0 \\
(8,1)\end{array}$ & $\begin{array}{l}23,5 \\
(4,7)\end{array}$ & $\begin{array}{c}9,0 \\
(3,2)\end{array}$ & $\begin{array}{c}0,9 \\
(1,7)\end{array}$ & $\begin{array}{c}7,0 \\
(2,2)\end{array}$ & $\begin{array}{l}67,4 \\
(13,6)\end{array}$ \\
\hline Portocel (ES) & $\begin{array}{l}27,9 \\
(2,4)\end{array}$ & $\begin{array}{l}25,8 \\
(1,7)\end{array}$ & $\begin{array}{l}37,0 \\
(1,6)\end{array}$ & $\begin{array}{c}9,3 \\
(0,1)\end{array}$ & $\begin{array}{l}72,8 \\
(1,8)\end{array}$ & $\begin{array}{l}24,5 \\
(1,3)\end{array}$ & $\begin{array}{c}2,8 \\
(1,2)\end{array}$ & $\begin{array}{c}0,0 \\
(0,0)\end{array}$ & $\begin{array}{l}72,7 \\
(1,4)\end{array}$ & $\begin{array}{c}0,0 \\
(0,0)\end{array}$ \\
\hline Portonave (SC) & $\begin{array}{c}68,9 \\
(10,7)\end{array}$ & $\begin{array}{c}7,3 \\
(2,2)\end{array}$ & $\begin{array}{l}56,8 \\
(6,5)\end{array}$ & $\begin{array}{l}10,7 \\
(0,6)\end{array}$ & $\begin{array}{l}62,7 \\
(4,8)\end{array}$ & $\begin{array}{c}2,6 \\
(2,9)\end{array}$ & $\begin{array}{c}0,0 \\
(0,0)\end{array}$ & $\begin{array}{c}0,0 \\
(0,0)\end{array}$ & $\begin{array}{c}0,0 \\
(0,1)\end{array}$ & $\begin{array}{l}99,8 \\
(0,4)\end{array}$ \\
\hline Praia Mole (ES) & $\begin{array}{l}22,5 \\
(4,2)\end{array}$ & $\begin{array}{l}20,4 \\
(3,6)\end{array}$ & $\begin{array}{l}34,9 \\
(2,5)\end{array}$ & $\begin{array}{c}8,3 \\
(0,1)\end{array}$ & $\begin{array}{l}76,3 \\
(5,7)\end{array}$ & $\begin{array}{l}10,3 \\
(4,9)\end{array}$ & $\begin{array}{l}47,7 \\
(6,1)\end{array}$ & $\begin{array}{c}0,0 \\
(0,0)\end{array}$ & $\begin{array}{l}49,8 \\
(5,9)\end{array}$ & $\begin{array}{c}0,1 \\
(0,5)\end{array}$ \\
\hline Super Terminais (AM) & $\begin{array}{l}11,9 \\
(3,8)\end{array}$ & $\begin{array}{l}17,5 \\
(2,4)\end{array}$ & $\begin{array}{l}23,4 \\
(3,0)\end{array}$ & $\begin{array}{c}8,1 \\
(0,2)\end{array}$ & $\begin{array}{l}80,1 \\
(8,8)\end{array}$ & $\begin{array}{l}30,9 \\
(13,9)\end{array}$ & $\begin{array}{c}0,7 \\
(2,2)\end{array}$ & $\begin{array}{c}0,0 \\
(0,0)\end{array}$ & $\begin{array}{c}3,1 \\
(4,5)\end{array}$ & $\begin{array}{l}96,2 \\
(6,2)\end{array}$ \\
\hline Ultrafértil (SP) & $\begin{array}{c}7,9 \\
(2,0)\end{array}$ & $\begin{array}{l}24,8 \\
(1,9)\end{array}$ & $\begin{array}{l}38,6 \\
(2,2)\end{array}$ & $\begin{array}{c}8,7 \\
(0,2)\end{array}$ & $\begin{array}{r}100,0 \\
(0,0)\end{array}$ & $\begin{array}{c}0,0 \\
(0,0)\end{array}$ & $\begin{array}{l}71,1 \\
(6,7)\end{array}$ & $\begin{array}{c}0,0 \\
(0,0)\end{array}$ & $\begin{array}{c}7,5 \\
(5,9)\end{array}$ & $\begin{array}{c}0,0 \\
(0,0)\end{array}$ \\
\hline Usiminas (SP) & $\begin{array}{l}14,4 \\
(3,7)\end{array}$ & $\begin{array}{l}\mathbf{2 8 , 4} \\
(2,7)\end{array}$ & $\begin{array}{l}45,0 \\
(3,1)\end{array}$ & $\begin{array}{c}8,7 \\
(0,2)\end{array}$ & $\begin{array}{l}81,5 \\
(8,0)\end{array}$ & $\begin{array}{c}9,4 \\
(5,5)\end{array}$ & $\begin{array}{l}73,7 \\
(8,6)\end{array}$ & $\begin{array}{c}0,0 \\
(0,0)\end{array}$ & $\begin{array}{l}26,0 \\
(8,4)\end{array}$ & $\begin{array}{c}0,2 \\
(0,6)\end{array}$ \\
\hline Yara Brasil (RS) & $\begin{array}{l}10,2 \\
(3,6)\end{array}$ & $\begin{array}{l}15,6 \\
(2,1)\end{array}$ & $\begin{array}{c}36,9 \\
(3,4)\end{array}$ & $\begin{array}{c}8,6 \\
(0,3)\end{array}$ & $\begin{array}{c}100,0 \\
(0,0)\end{array}$ & $\begin{array}{c}0,0 \\
(0,0)\end{array}$ & $\begin{array}{l}78,4 \\
(9,9)\end{array}$ & $\begin{array}{l}13,6 \\
(7,1)\end{array}$ & $\begin{array}{c}7,8 \\
(5,3)\end{array}$ & $\begin{array}{c}0,0 \\
(0,0)\end{array}$ \\
\hline
\end{tabular}




\section{Apêndice 2}

Resultados estimados para os casos onde não há evidencia de resultados positivos - as linhas preta, tracejada e cinzas representam, respectivamente, as trajetórias observada, sintética e placebos para a movimentação média por navio.

\begin{tabular}{|l|cc|}
\hline Preditor & Observado & Sintético \\
\hline Movimentação & 51,4 & 45,3 \\
DWT & 83,2 & 43,9 \\
Calado & 11,0 & 8,9 \\
Longo curso & 78,5 & 44,2 \\
Brasileiros & 16,1 & 18,2 \\
G. de sólidos & 38,8 & 71,2 \\
G. de líquidos & 0,0 & 12,9 \\
Carga Geral & 3,3 & 15,6 \\
Conteineiros & 54,9 & 0,0 \\
& & \\
\hline
\end{tabular}

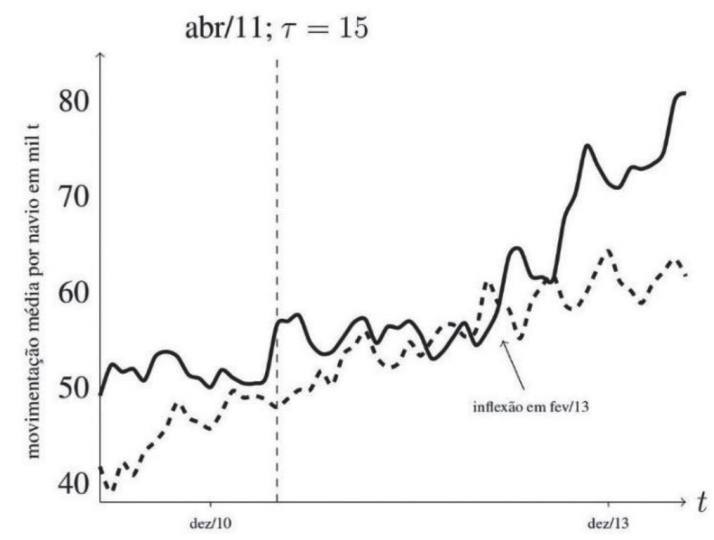

Figura A.1 - Itaguaí (RJ)

\begin{tabular}{|l|cc|}
\hline Preditor & Observado & Sintético \\
\hline Movimentação & 6,6 & 6,8 \\
DWT & 44,6 & 45,9 \\
Calado & 9,7 & 9,8 \\
Longo curso & 69,9 & 64,3 \\
Brasileiros & 7,3 & 12,7 \\
G. de sólidos & 0,1 & 2,0 \\
G. de líquidos & 0,0 & 1,2 \\
Carga Geral & 0,4 & 2,1 \\
Conteineiros & 99,2 & 93,1 \\
& & \\
\hline
\end{tabular}

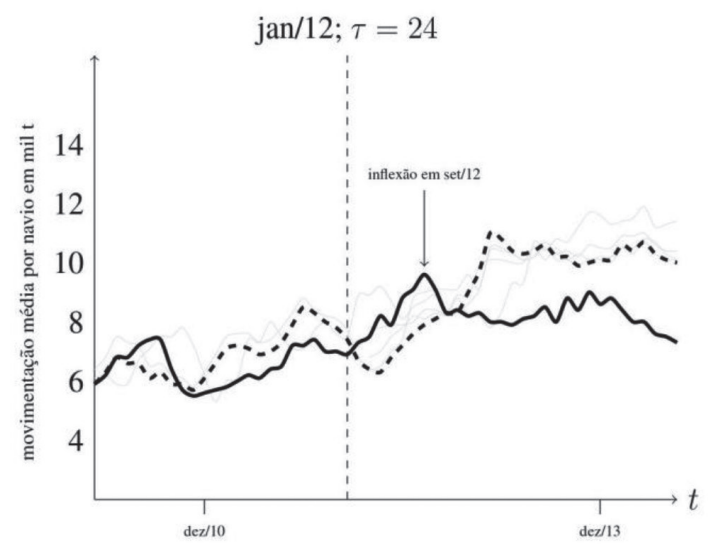

Figura A.2 - Itajaí (SC) 


\begin{tabular}{|l|cc|}
\hline Preditor & Observado & Sintético \\
& & \\
\hline & & \\
Movimentação & 4,2 & 5,0 \\
DWT & 20,6 & 50,0 \\
Calado & 7,9 & 10,0 \\
Longo curso & 80,6 & 66,3 \\
Brasileiros & 1,2 & 5,2 \\
G. de sólidos & 16,9 & 0,0 \\
G. de líquidos & 0,0 & 0,0 \\
Carga Geral & 16,2 & 0,2 \\
Conteineiros & 63,4 & 99,4 \\
& & \\
\hline
\end{tabular}

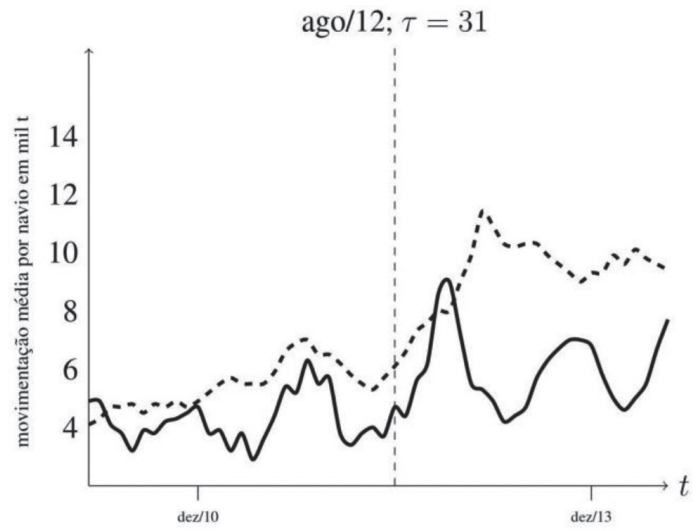

Figura A.3 - Natal (RN)

\begin{tabular}{|l|cc|}
\hline & & \\
& Observado & Sintético \\
\hline & & \\
Movimentação & 4,6 & 5,5 \\
DWT & 40,5 & 44,9 \\
Calado & 9,2 & 9,7 \\
Longo curso & 71,3 & 68,5 \\
Brasileiros & 2,5 & 14,8 \\
G. de sólidos & 5,1 & 10,0 \\
G. de líquidos & 4,5 & 0,2 \\
Carga Geral & 14,1 & 5,7 \\
Conteineiros & 67,2 & 81,2 \\
& & \\
\hline
\end{tabular}

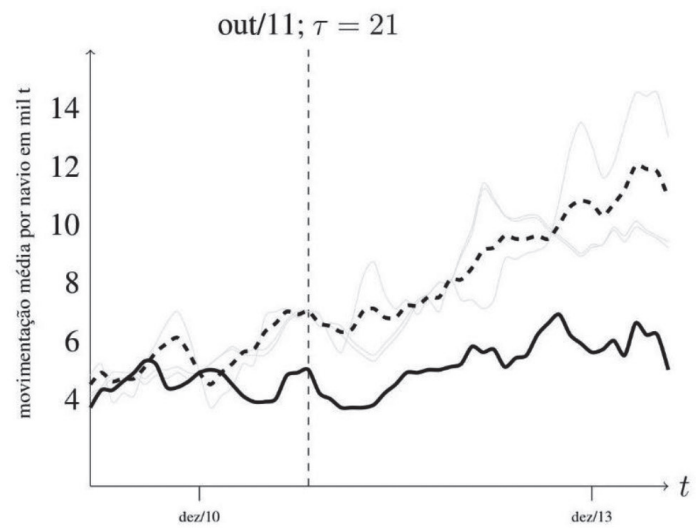

Figura A.4 - Rio de Janeiro (RJ) 


\begin{tabular}{|l|cc|}
\hline Preditor & Observado & Sintético \\
\hline & & \\
\hline Movimentação & 3,8 & 5,0 \\
DWT & 38,1 & 49,8 \\
Calado & 9,3 & 10,0 \\
Longo curso & 60,6 & 66,4 \\
Brasileiros & 30,1 & 2,3 \\
G. de sólidos & 3,0 & 0,0 \\
G. de líquidos & 1,0 & 0,0 \\
Carga Geral & 9,2 & 0,2 \\
Conteineiros & 83,0 & 99,4 \\
& & \\
\hline
\end{tabular}

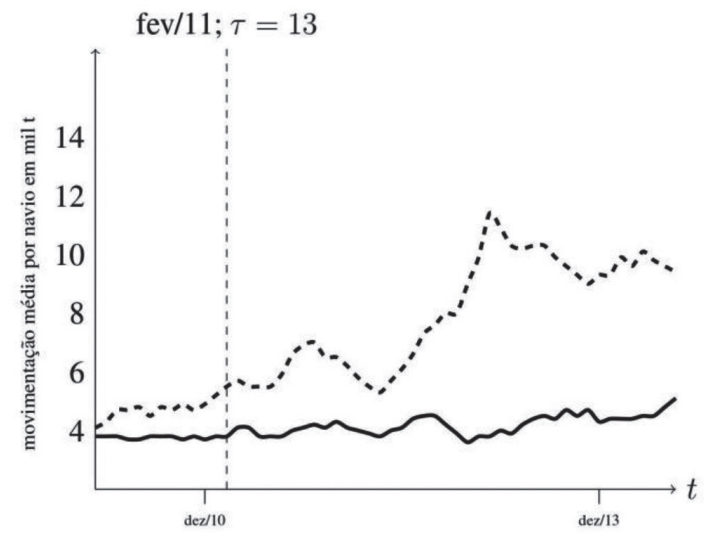

Figura A.5 - Salvador (BA)

\begin{tabular}{|l|cc|}
\hline Preditor & Observado & Sintético \\
\hline & & \\
\hline Movimentação & 18,8 & 18,7 \\
DWT & 47,7 & 46,7 \\
Calado & 9,7 & 9,4 \\
Longo curso & 72,7 & 73,8 \\
Brasileiros & 6,3 & 5,3 \\
G. de sólidos & 19,3 & 30,3 \\
G. de líquidos & 13,5 & 15,8 \\
Carga Geral & 8,5 & 10,0 \\
Conteineiros & 51,7 & 34,8 \\
& & \\
\hline
\end{tabular}

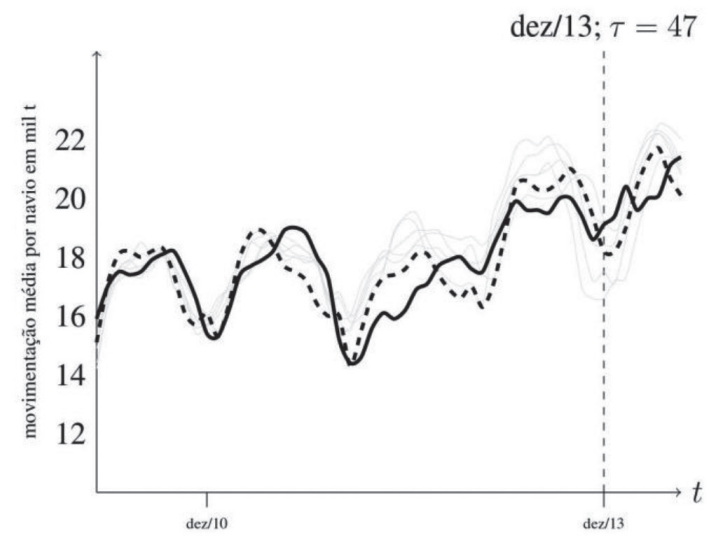

Figura A.6 - Santos (SP) 


\begin{tabular}{|l|cc|}
\hline Preditor & Observado & Sintético \\
\hline & & \\
Movimentação & 6,7 & 6,8 \\
DWT & 42,3 & 40,5 \\
Calado & 9,3 & 9,3 \\
Longo curso & 47,1 & 59,7 \\
Brasileiros & 22,1 & 16,9 \\
G. de sólidos & 4,0 & 5,1 \\
G. de líquidos & 15,9 & 16,7 \\
Carga Geral & 5,1 & 5,0 \\
Conteineiros & 63,0 & 67,3 \\
& & \\
\hline
\end{tabular}

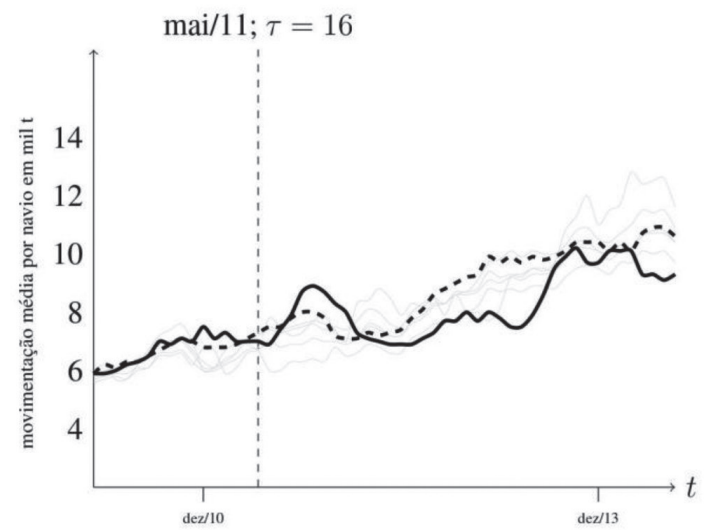

Figura A.7 - Suape (PE) 